\title{
Are employee stock option exercise decisions better explained through the prospect theory?
}

\begin{abstract}
This research provides an alternative framework for the analysis of employee stock option exercise patterns. It develops a binomial model where the exercise decision obeys to a policy that maximizes the expected utility to a representative employee exhibiting preferences as described by the Cumulative Prospect Theory (CPT). Using a large database on exercise transactions in 12 US public corporations, I examined the performance of the model in predicting actual exercise patterns. Interestingly, the probability weighting coefficients yielded by the model calibration are consistent with those from the experimental literature. Further, the results suggest that the model outperforms the Expected Utility Theory-based model in predicting actual exercise decisions in the sample. These findings convey the main contribution of this paper: the strong ability of the CPT framework to explain employees exercise behavior. It therefore provides rationale for using this framework in order to get more relevant fair value estimates of stock options.
\end{abstract}

JEL Classification: G13, G30, J33, M41.

Keywords: Stock options, Exercise behavior, Cumulative Prospect Theory, Fair value, Option valuation. 


\section{Introduction}

The extensive use of stock options in employee compensation packages and their increasing popularity as long term incentive tools have brought many of their corporate issues at the forefront of public debate. Professionals and regulators have become specifically concerned about assessing their cost to shareholders. This issue has been intensified by the requirements of the accounting standards (IFRS and US GAAP) from public companies to fairly recognize the cost of stock options grants. Thus suitable expensing of employee stock options has become a focus of attention in financial accounting.

The complexity with the assessment of the stock options fair value is that their payoffs depend on the exercise behavior of the holder. This behavior deviates from the usual value-maximizing exercise policy stated by the standard American options theory because of many reasons. First, opposite to ordinary tradable call options, employee stock options are long-dated nontransferable ${ }^{1}$ call options. This implies that the employee has to bear the underlying risk for a long time. Second, the employee faces hedging restrictions since he is usually precluded from short selling the company's stock. Finally, stock option holder may be unable to completely diversify his stock holdings and human capital investment in the firm. Because of these features, the employee will not make the same exercise decision as an unrestricted outside investor. Therefore, the fair value of his stock option contract crucially depends on his endowment and on his risk preferences patterns.

Given that the values of employee stock options are not observable, their valuation requires a theoretical modeling of the exercise policy of the beneficiary. There is an extensive literature focused on this issue. Most of it relies on the Expected Utility Theory (EUT henceforth) to develop utilitymaximizing binomial models (Huddart, 1994; Kulatilaka and Markus, 1994; Carpenter, 1998). These approaches consider that the employee chooses an optimal exercise decision as part of a utility maximization problem that may simultaneously cover other issues such as consumption and portfolio choices (Detemple and Sundaresan, 1999), non-option wealth diversification or liquidity needs. Nonetheless, these models specifically rely on the validity of the underlying theoretical framework, namely the EUT.

Beyond the well known limitations of the standard normative model in explaining some patterns of economic agent behavior, it has shown handicaps in capturing some prominent features of employee equity-based compensation. For instance, EUT-based models, taking place in the principalagent framework, have difficulties accommodating the existence of convex contracts as part of the executive compensation package ${ }^{2}$. Consistently, studies focused on the effect of stock option and

\footnotetext{
${ }^{1}$ Market experience shows however some exceptions to this feature, such like the transferable stock options programs developed by JP Morgan Chase for Microsoft in July 2003 and for Comcast in September 2004. According to this deal, JP Morgan offers the entitled employees to purchase their underwater stock options at a discount premium (i.e. below their potential market value).

${ }^{2}$ This issue is meticulously discussed in Dittmann and Maug (2007) and in Dittmann et al. (2010).
} 
restricted stock grants on managerial effort incentives, such like Jenter (2001), Hall and Murphy (2002) and Henderson (2005), conclude that stock options are inefficient tools for creating incentives for risk-averse managers when they are granted by mean of an offset of cash compensation. This is obviously inconsistent with actual compensation practices. Moreover, a common prediction of the EUT-based models is that a risk-averse undiversified employee would value his options below their risk-neutral value (Lambert et al., 1991; Hall and Merphy; 2000, 2002; Henderson, 2005), which contrasts to several surveys and empirical findings documenting that, frequently, employees are inclined to overestimate the value of their stock options compared to the theoretical fair market value (Lambert and Larcker, 2001; Hodge et al., 2010; Hallock and Olson, 2006; Devers et al., 2007). Furthermore, there is an empirical evidence on employees decisions, and specifically those related to the exercise of their stock options (Huddart and Lang, 1996; Heath et al., 1999), being driven by psychological and behavioral factors that are out of the scope of the EUT. Actually, these limitations of the EUT framework provide rationale and motivation for investigating the ability of an alternative theoretical framework to better predict employee stock option exercise patterns.

This paper develops a stock option valuation model where the exercise decision obeys to a policy that maximizes the expected utility of a representative employee exhibiting preferences as described by Tversky's and Kahneman's (1992) Cumulative Prospect Theory (CPT hereafter). The model also accounts for exogenous non-market factors that may cause early exercise through an exit state that occurs with a given probability. This research aims to provide an alternative framework for the valuation of employee standard stock options and the analysis of the exercise behavior patterns. The purpose of this work is also to contribute to a growing literature on employee equity-based compensation that incorporates CPT-based models. These models have proved successful in explaining some observed compensation practices, and specifically the almost universal presence of stock options in the executive compensation contracts. Therefore, they have advanced the CPT framework as a promising candidate for the analysis of equity-based compensation. This literature includes in particular Dittmann et al. (2010) who developed a stylized principal-agent model that explains the observed mix of restricted stocks and stock options in the executive compensation packages. It also includes Spalt (2013) who used the CPT framework, and especially the probability weighting feature, to prove that stock options may be attractive to a loss-averse employee subject to probability weighting. He then explained the puzzling phenomenon that riskier firms are prompted to grant more stock options to non-executive employees. This literature comprises also Bahaji's (2011) work that elaborates on stock options incentives effect and some implications in terms of contract design aspects.

Further, I examined the performance of the CPT model in explaining actual exercise decisions in 12 US public firms over the period from 1985 to 2007. Specifically, I compared the model performance to those of two competing models, namely the EUT-based binomial model (EU model 
hereafter) introduced in Carpenter (1998) and the stopping-state American model (EA model in the reminder of the paper). The latter is a binomial version of Jennergren and Naslund (1993) continuoustime model. Given that some factors underlying the models are not observable, I calibrated the models on the average data from the sample. The statistical significance tests show that the models fit the mean data remarkably well. Interestingly, the calibration of the CPT model yields values of the probability weighting parameter that lie within the range of the experimental estimates. Next, I compared the performance of the parameterized models in predicting actual exercise stock price ratios in the sample. I found that the CPT model brings a significant improvement over the EU model and the EA model in terms of both in-sample and out-of-sample forecast errors. Therefore, the CPT framework turns out to be the best candidate in explaining empirical exercise decisions.

The last item discussed in this paper relates to the implications in terms of cost to shareholders. I assessed the values of the option contracts in the sample at inception under each of the three competing models. In addition, for the purpose of comparison with some methods recommended by the international accounting standards and largely used by practitioners, I computed option fair values using two benchmark models. The first one is the extension of the Black \& Scholes model (BS henceforth) that uses the expected lifetime of the option as an input instead of its contractual expiration date. The second benchmark is the Hull and White (2004) model. The results show that, on the one hand, the CPT model yields comparable values to those from the EU model but higher than those from the EA model and that, on the other hand, the values from the benchmark models are significantly lower than the values computed based on the CPT model. Specifically, if we consider the latter to be the most accurate model in the sense that it leads to improved predictions of exercise decisions, we would admit that the benchmark models would underestimate the stock options values by $4 \%$ to $13 \%$.

The remainder of the paper is structured as follows. In the first section the literature related to stock option exercise and valuation is reviewed. The second section sketches a theoretical framework for stock option exercise from the perspective of a CPT representative employee and describes the piecewise construction of the model. Section 3 presents the empirical comparative analysis. The last section discusses the implications in terms of fair value assessment.

\section{Stock option exercise and valuation: related literature}

With the increasing interrogations surrounding the use of employee stock options, their exercise and valuation issues have become a focus of interest of a rapidly growing literature. This literature includes several empirical studies that attempted to bring the spotlight on the determinants of early exercise patterns. Hemmer et al. (1996), Core and Guay (2001) and Bettis et al. (2005) investigated economic (or rational) factors driving exercise decisions such as liquidity needs and risk diversification. Huddart and Lang (1996) studied the exercise behavior over 50,000 employees at eight 
corporations. They mainly found that the exercise decisions are strongly associated with recent stock price movements. Heath et al. (1999) have found empirical evidence suggesting that psychological factors may also lead the employee to sacrifice some option value through early exercise. Consistently, Sautner and Weber (2005) provided some interesting empirical results supporting that employees exercise behavior denotes psychological bias, such as miscalibration and mental accounting. This line of studies also includes Core and Guay (2001), Misra and Shi (2005) and Armstrong et al. (2006). All these studies provide rationale for behavioral factors to be considered in a theoretical framework for employees exercise decisions.

One approach that has been suggested in the literature to address the problem of nontransferability and hedging restrictions effects on exercise behavior is to model the employee exercise policy relying on the EUT framework. These papers characterized the optimal exercise policy by a utility-maximization problem. Huddart (1994) and Kulatilaka and Marcus (1994) were the first to have introduced binomial models where the exercise occurs as soon as the utility from the exercise proceeds exceeds the expected utility from holding the option for another period, with non-option wealth invested in the risk-free asset. Carpenter (1998) extended this approach to take into account early exercise or forfeiture due to job termination, using an exogenous Poisson process with a given stopping rate ${ }^{3}$. Another improvement brought by Carpenter (1998) is the investment of the employee non-option wealth in the Merton optimal portfolio instead of the risk-free asset. She calibrated her model to mean exercise data from a sample of 40 US firms. She found that, surprisingly, the EU model performs almost as good as a simple extension of the usual binomial model including an exogenous stopping state, which suggests that "exercise patterns can be approximately replicated merely by imposing a suitable stopping rate, without the need to make assumptions about [...] risk aversion, diversification, and the value of new employment". Detemple and Sundaresan (1999) suggested an extension that allows for simultaneous portfolio choice and stock option exercise decisions. Bettis et al. (2005) built on Carpenter's (1998) approach to carry out an analysis of exercise patterns within a sample of 140,000 option exercises by corporate executives at almost 4,000 firms. They calibrated the EU model to their median data. Their results contrast with those of Carpenter (1998) in that they show that the EU model outperforms the stopping state binomial model in forecasting exercise patterns.

Another line of studies has advocated approaches based on an exogenous specification of the exercise policy. Rubinstein (1994) and Cuny and Jorion (1995) built stock option pricing models under exogenous assumptions about the exercise timing. Jennergren and Naslund (1993) and Carr and Linetsky (2000) derived analytical valuation formulas assuming exogenous forfeiture rates and exercise boundaries. Moreover, a paper by Hull and White (2004) proposed a binomial model

\footnotetext{
${ }^{3}$ Papers that focused on the impact on the stock option fair value of forfeiture and early exercise due to job termination include Jennergren and Naslund (1993), Cuny and Jorion (1995) and Rubinstein (1995).
} 
assuming that vested options are exercised whenever the stock price hits an exogenous hurdle specified as a multiple of the stock price at inception. Their approach also allows for the possibility that the option holder might have to leave the firm for exogenous reasons and, therefore, needs to forfeit or exercise his options provided these are in-the-money. Relying on Hull's and White's approach, Cvitanic et al. (2004) provided an analytical pricing formula. Carpenter et al. (2010) showed, however, that the optimal exercise policy needs not to be specified in the form of a single critical stock price boundary. They nevertheless proved under the risk-neutral probability measure the existence of a single stock price exercise boundary for CRRA utility functions with risk aversion coefficient less than or equal to one.

More recent literature has underscored the relevance of valuation approaches that proceed by using empirically estimated exercise hazard functions to describe the stock option's expected payoff. Carpenter et al. (2006) suggested a method - similar to that used for the modeling of the prepayment of the mortgage-backed securities - relying on estimated exercise and cancellation rates as a hazard function of the stock price path, time to expiration and both firm and option holder characteristics. Armstrong et al. (2006) modeled exercise rates as a function of idiosyncratic behavioral and economic factors such as attainment of performance benchmarks, recent vesting, portfolio value, and employee rank. They proved that estimates from an idiosyncratic exercise rate model are also more accurate in predicting out-of-sample realized option values.

Finally, several researches have attempted to undertake the issues related to the effects of reloading and resetting features on stock options exercises and valuation (Hemmer et al., 1998; Saly et al., 1999; Dybvig and Loewenstein, 2003), whilst other studies have focused on valuation issues related to block exercise behavior (Henderson, 2006; Grasselli and Henderson, 2009).

\section{The CPT exercise model}

This section develops a model of stock options exercise and valuation from the viewpoint of the issuer (i.e. the firm). The model is based on a theoretical framework where the option cash flows depend on the exercise behavior of a representative option holder whose risk preferences fit with the CPT framework.

\subsection{The economy of the stock option contract}

The representative employee is assumed to be granted a stock option contract at time $t=0$ expiring within a time period " $T$ ". The contract is a Bermudan style call option on the common stock of the company denoted by " $S_{t}$ ", with a strike price " $K$ ". It includes two restrictions as commonly do standard employee stock options. The first one is the non-transferability, which means that the employee is precluded from selling the option. The second one is the vesting, which implies the 
Bermudan feature of the option. The vesting restriction requires the cancellation of the contract in case the holder leaves the company before the end of the vesting period " $t_{v}$ ". In addition, I assumed that the employee is not allowed to short-sell the company stock and that he can earn the risk-free rate " $r$ " from investing in a riskless asset. This assumption stands then for a restriction on the option hedging.

Moreover, the underlying is assumed to follow a standard binomial process with " $N$ " time steps. Thus, in each time step " $\delta t=T / N$ " the stock price may move up by a factor " $u=e^{\sigma \sqrt{\delta t}}$ " with a probability " $p=\frac{e^{(\mu-q) \cdot \delta t}-u}{u-1 / u}$ " or down by factor " $d=1 / u$ ". The parameters " $\sigma$ ", " $\mu$ " and " $q$ " are respectively the stock price volatility, the expected return and the dividend yield. Recall that the upward risk neutral probability writes: $p^{*}=\frac{e^{(r-q) . \delta t}-u}{u-1 / u}$.

Furthermore, following Carpenter (1998), I assumed that at each time period there is an exogenous probability " $p_{e}$ " for the employee to be offered a cash amount " $y$ " per option held in order to leave the company. Leaving the company implies that the option contract is stopped at that time either through exercise, provided the option is vested and is in-the-money, or via forfeiture otherwise.

\subsection{Risk preferences of the representative employee}

I assumed that the representative employee exhibits preferences as described by the CPT (Tversky and Kahneman, 1992). It follows that to each gamble " $x$ " with countable outcomes " $x_{i \in\{1, \ldots, n\}}$ " and their respective probabilities “ $p_{i \in\{1, \ldots, n\}}$ ”, the employee assigns the value:

$$
V(x)=\sum_{i=1}^{n} \omega_{a, i} v_{\theta}\left(x_{i}\right)
$$

Where the function $v_{\theta}($.$) , called the value function, is assumed of the form:$

$v_{\theta}(y)=\left\{\begin{array}{c}(y-\theta)^{\alpha} ; y \geq \theta \\ -\lambda(\theta-y)^{\alpha} ; y<\theta\end{array}\right.$, where $0<\alpha \leq 1$ and $\lambda \geq 1$

This formulation has some important features that distinguish it from the normative utility specification. The value function is defined on deviations from a reference point, denoted by " $\theta$ ". It is concave for gains (i.e. implying risk aversion) and commonly convex for losses (i.e. implying risk seeking) due to parameter " $\alpha$ ". It is steeper for losses than for gains (i.e. conveying a loss aversion feature caught up through " $\lambda$ ”). 
The terms " $\omega_{a, i}$ " in (1) are decisions weights associated to each outcome. These result from a transformation of the probabilities using a weighting function " $\psi_{a}($.$) ". The transformation applies to$ cumulative probabilities, represented by the cumulative probability function " $F($.$) ”, as follows:$

$\omega_{a, i}=\left\{\begin{array}{l}\psi_{a}\left(\sum_{j=1}^{i} p_{j}\right)-\psi_{a}\left(\sum_{j=1}^{i-1} p_{j}\right)=\psi_{a}\left(F\left(x_{i}\right)\right)-\psi_{a}\left(F\left(x_{i-1}\right)\right) ; i>1 \\ \psi_{a}\left(p_{i}\right) ; i=1\end{array}\right.$

Following Tversky and Kahneman (1992), the probability weighting function is assumed of the form:

$\psi_{a}(p)=\frac{p^{a}}{\left(p^{a}+(1-p)^{a}\right)^{\frac{1}{a}}} \quad$ where $0.279<a \leq 1$

This function stands for another piece of the CPT, which is the nonlinear transformation of probabilities. Specifically, it captures experimental evidence on people overweighting small probabilities and being more sensitive to probability spreads at higher probability levels. As we cen see from equation (3), in contrast with the CPT, but consistent with Rank Dependent Expected Utility theory (Quiggin, 1982), the weighting of probabilities described is identically performed over gains and losses so that decision weights sum to one. The degree of weighting is controlled by the parameter " $a$ ". The more this parameter approaches the lower boundary ${ }^{4}$ at 0.279 the more the tails of the probability distribution are overweighted. For instance, when " $a$ " is set to 1 , the probability weighting assumption is relaxed.

\subsection{Setting up the CPT model}

Using an alternative behavioral framework, the CPT model builds on prior works by Huddart (1994), Kulatilaka and Marcus (1994) and Carpenter (1998) in that it uses the same principle governing the exercise decision. Similar to these models, the CPT model is a two-state lattice where the optimal exercise decision is driven by the maximization of the expected utility from the exercise proceeds. According to this maximization principle, the option is exercised at a given time period if the utility from the exercise proceeds is higher than the expected utility from continuing to hold the option until the next time period. With that said, the representative employee is supposed to exercise as soon as the intrinsic value of the option exceeds the value of the option from his own perspective (i.e. the subjective value). However, opposite to these models, the utility is assessed using the CPT

\footnotetext{
${ }^{4}$ The lower boundary at 0.279 is a technical restriction to insure that " $\partial \psi_{a}(p) / \partial p$ " is positive over ]0,1[ as required by the following first order condition: $(a-1) p^{a}+(a(1-p)+p)(1-p)^{a} \geq 0$. This constraint insures that the probability weighting function can not assign negative decision weights consistent with first-order stochastic dominance. For further details see Ingersoll (2008).
} 
framework instead of the EUT. Therefore, the key differentiating point is that, on the one hand, only the utility of exercise proceeds is considered rather than that of total wealth and, on the other hand, the expected utility is assessed based on weighted probabilities.

\subsubsection{Model construction}

The first step of the CPT model construction consists in determining the transition decision weights that will be used to assess the utility expectation at each node of the binomial tree. The purpose is to build in parallel to the share price binomial process a two-state decision weights process that fits with the employee view of probabilities as specified by the CPT probability weighting function $^{5}$ in (4). This process relies on a decision weights tree with the same share price nodes as the binomial tree. The approach used to build this tree is described through the set of equations in appendix A1. As stated, this approach keeps the original share price nodes unchanged and uses forward induction to recover all transition decision weights starting from the root of the tree.

The second step is about setting the patterns of exercise decision. Following Carpenter (1998), I accommodate the possibility of option forfeitures or early exercises caused by non-market events, such as liquidity shocks, employment termination or any other forced exercise through the exit states. Note that the exit decision is an endogenous feature of the model in that it is linked to the size of the cash amount " $y$ " offered to the employee to quit. In addition, I assumed that the exercise decision at a given time period depends on whether or not the exit state is prevailing at that time, on the vesting status of the option and on the prevailing level of stock price, but not on the past stock price path. This assumption allows for backward recursion.

Moreover, as stated in assumption 1 bellow, the employee is assumed to set his reference point based on his initial own share price return expectations over the lifetime of the option:

Assumption 1: the reference point " $\theta_{i}$ " at a time period " $t_{i}$ " is defined as the intrinsic value resulting from a time-adjusted growth rate of the share price based on the annualized return " $\rho$ " reflecting the expectations of the employee:

$\theta_{i}=\left(S e^{(\rho-q) i \delta t}-K\right)^{+}$

While this setting is inconsistent with empirical evidence on employee exercise activity being linked to share price historical maxima (Huddart and Lang, 1996; Heath et al, 1999), it nevertheless conveys an exercise behavior taking into account non-status quo reference points. Actually, under a

\footnotetext{
${ }^{5}$ An interesting alternative to the CPT probability weighting function is using weighting functions implied by listed options prices. This approach uses non-parametric methods to estimate state price densities from options market prices. These estimates are then used as building blocks to construct non-parametric estimators of the weighting function without imposing any constraint on the shape of the former. For more details on this approach see Polkovnichenko and Zhao (2013).
} 
path-dependent specification of the reference point, backward recursion becomes impossible in our situation. The specification in (5) is also supported by Hodge et al. (2010) findings that employees usually use heuristics to attach values to their stock options, like determining the intrinsic value from their expectations about future stock price. Recall that although the CPT specifies the shape of the value function around the reference point, it does not provide guidance on how people set their reference points. Neither does most of the psychological literature relying on the assumption according to which the reference point is the Status quo. Instead, this literature admits both the existence and the importance of non-status quo reference points since "there are situations in which gains and losses are coded relative to an expectation or aspiration level that differs from the status quo" (Kahneman and Tversky, 1979). Research on the Disposition Effect ${ }^{6}$ has paid greater attention to this issue (Shefrin and Statman, 1985; Heisler, 1998; Odean, 1998). These studies have found strong evidence on reference points being set in a dynamic fashion. Moreover, literature on reference point adaptation is still developing. This literature includes few papers such as Koszegi and Rabin (2006) and Yogo (2005) that posit that people set their reference point based on their expectations about the future instead of the starting point (ex: original purchase price). It also includes researches that provided experimental evidence on people using historical maxima as reference points (Gneezy, 1998), shifting their reference points after a stimulus is presented (Chen and Rao, 2002) and adapting them asymmetrically more completely over gains than over losses (Arkes et al., 2006).

Finally, I made the following assumption regarding block exercise (i.e. policy of spreading exercise over several separate transactions) that implies an "all or nothing" exercise policy in the model:

Assumption 2: when the employee decides to exercise, he will do so for all his outstanding options at once in a single block provided these options are part of the same grant and, therefore, have the same characteristics.

Figure- 1 exhibits the structure of the model at the $j^{\text {th }}$ node of the $i^{\text {th }}$ level of the tree (i.e. at time " $t_{i}=i . \delta t$ ") denoted by $(i, j)$. The option is assumed to have already vested at that level. As illustrated, the exercise decision relies on the subjective value of the option considering four states of the world (i.e. stopping/continuing states combined with upward/downward sates). The latter is assessed over these four states based on the certainty equivalence principle using the transition decision weights and the exit probability. Thus, in the continuing state, the option is exercised as soon as the intrinsic value exceeds the subjective value of the option. However, in the exit state, the employee decides to continue with the option if its subjective value is greater than the sum of its intrinsic value and the cash amount he has been offered to leave the company. By repeating this process using backward

\footnotetext{
${ }^{6}$ Disposition effect is a term coined by Shefrin and Statman (1985) to refer to the tendency of individual investors to hold loser stocks and sell winner stocks defined relative to a purchase price reference point.
} 
recursion, and starting from the end of the tree, we can find out the nodes where the option is exercised. Note that at the levels where the option is still unvested, it is systematically held to the next period provided the employee is in the continuing state. Nevertheless, an unvested option is forfeited in the exit state if its subjective value is lower than the exit-cash amount. A formal algorithm describing the discussed exercise rule is provided in the appendix A2.

Figure-1: Illustration of the CPT model construction.

This figure exhibits the structure of the CPT model tree at node $(i, j)$. The upper branches represent the exit state. Equation $(5.1)$ formulates the exercise outcome related to that state. Equation (5.2) gives the exercise outcome at the continuing state represented by the lower branches. Equations (5.3) and (5.4) provide, respectively, the option risk neutral value and subjective value.

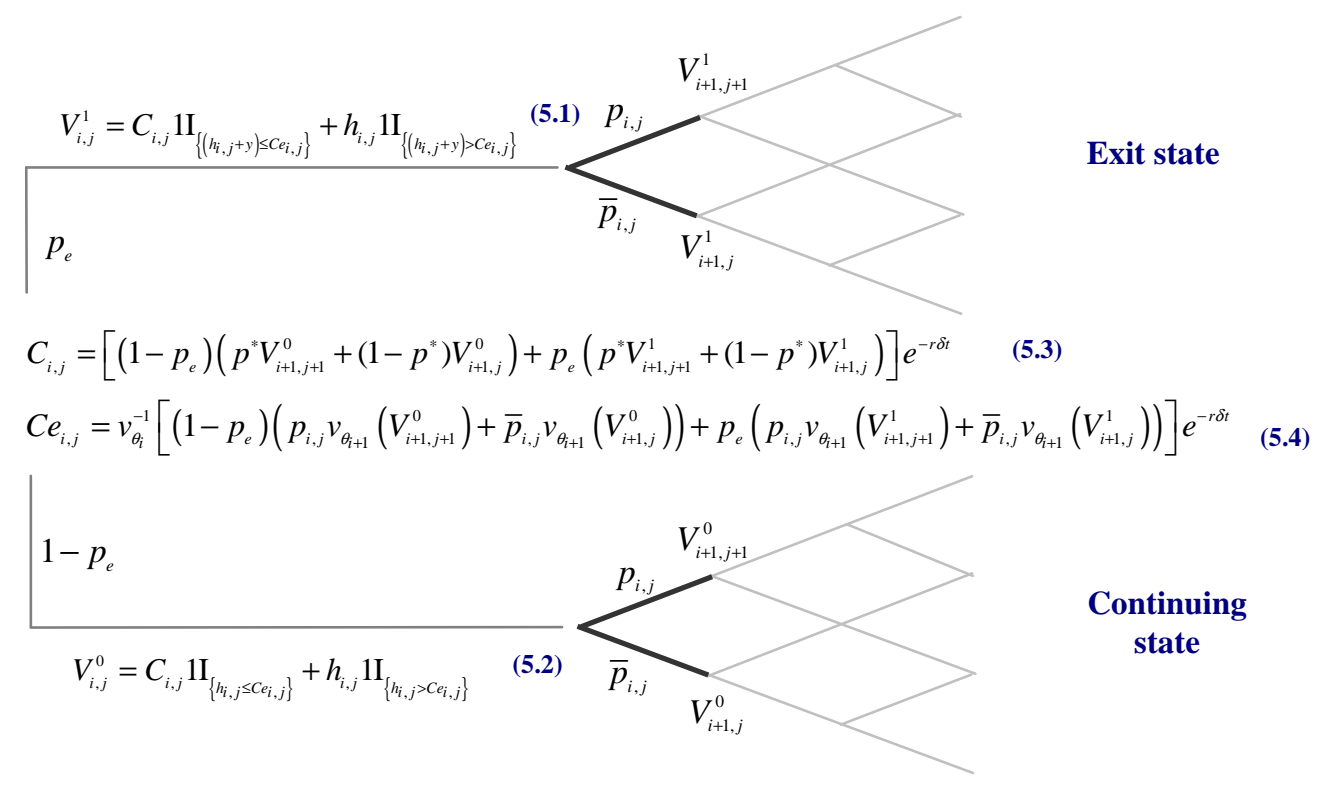

Notation

- $h_{i, j}$ : Intrinsic value of the option at note $(i, j)$.

- $p_{i, j}$ : Upward transition decision weight at node $(i, j)$.

- $\bar{p}_{i, j}$ : Downward transition decision weight at node $(i, j)$.

- $p^{*}$ : Risk neutral transition probability at node $(i, j)$.

- $C e_{i, j}$ : Subjective value of the option at node $(i, j)$ determined based on the certainty equivalence principle.

- $C_{i, j}$ : Risk-neutral value of the option at node $(i, j)$.

- $V_{i, j}^{0}$ : Continuing state exercise decision outcome at node $(i, j)$.

- $V_{i, j}^{1}$ : Exit state exercise decision outcome at node $(i, j)$.

- $\theta_{i}$ : Reference point at the $i^{\text {th }}$ level of the tree.

\subsection{2. $\quad$ Model outputs and predictions}

I considered that the employee exercise patterns are adequately characterized by the exercise stock price ratio denoted by " $S_{\tau}$ ". This variable is defined as the stock price-to-strike price ratio at the time of exercise " $\tau$ ". This assumption relies on the argument that the exercise decision is mainly driven by the utility procured by the exercise proceeds. It follows that the model-yielded statistic of interest predicting the exercise patterns is the expectation of the exercise stock price ratio subject to the terminal stock price:

$\hat{S}_{\tau}=I E^{p}\left(S_{\tau} \mid s_{T}^{*}\right)$

where "IE $E^{p}(. \mid$.$) " is the conditional expectation operator under the real probability measure.$ 
Specifically, the expectation above is determined as the weighted average of the outcomes of the random variable " $S_{\tau}$ " across all the stock price paths that result in an exercise and settle at a final stock price level " $s_{T}^{*}$ ". Note that this prediction takes into account the effect of the stock price effective performance on the exercise behavior since it is conditioned on the terminal stock price level. This makes it comparable to equivalent mean values from empirical data, which enables to test the model prediction power and to estimate the unobservable parameters.

The expected value of the cancellation rate " $\eta$ " is another model-yielded variable that has to be considered for the purpose of calibration on empirical data:

$\hat{\eta}=I E^{p}(\eta)$

The estimation of this statistic consists in recursively computing the 1-year cancellation probability based on the implied distribution of the cancellation state variable across all share price paths. Therefore, it may be interpreted as the average ratio of cancelled options during a year either through forfeitures or expirations. Note that, opposite to the previous statistic in (6), the mean cancellation rate is not conditioned on a final share price level. Let's also stress that the cancellation rate has to be distinguished from the exit rate. The latter is the model input that drives the frequency of forfeitures prior to the expiry date, whereas the former is a model output that results from the implied exercise policy and, consequently, depends on the model parameters and especially the exit rate.

\section{The empirical analysis}

In this section, I examine the performance of the CPT model in predicting actual exercise patterns in 12 US firms over the period from 1985 to 2007. Specifically, I compare the model performance to those of two competing models, namely the EU model and the EA model.

The EU model used is similar to that introduced by Carpenter (1998) and later empirically tested by Bettis et al. (2005) ${ }^{7}$. As in Huddart (1994) and Kulatilaka and Marcus (1994), this model is based on a binomial stock price tree where the exercise decision is made according to a policy that maximizes the expected utility subject to the hedging restrictions. The option holder utility function is assumed to be of the isoelastic form: " $u(w)=w^{1-\gamma} /(1-\gamma)$ ", where " $\gamma$ " is the constant relative risk aversion coefficient and " $w$ " is the employee outside wealth (i.e. non-option holding wealth) normalized by the value of his options underlying stocks. Moreover, similar to the CPT model, at each time step there is an exogenous probability " $p_{e}$ " for the employee to be offered a cash amount " $y$ " that motivates him to leave the firm. This allows accommodating the possibility of option forfeiture or an early exercise due to non-market events. In addition, the outside wealth as well as any early exercise

\footnotetext{
${ }^{7}$ The version used in this research ignores the leaving amount " $y "$.
} 
proceeds are assumed to be invested in the constant proportion portfolio of the company's stock and a risk-free bond that would be optimal for the employee to hold in the absence of the stock option and the possibility of receiving " $y$ ". This optimal portfolio is a binomial version of the continuous-time portfolio developed by Merton $(1969,1971)$. For further details regarding the EU model algorithm the reader is referred to Carpenter (1998).

The EA model is a binomial variant of the continuous-time model of Jennergren and Naslund (1993). The only difference between this model and the standard American option model is the stopping event that occurs with some exogenous probability " $p_{e}$ ". This exit state captures all the factors that might cause a deviation from the standard theory exercise policy such as employment termination, liquidity needs or a desire for diversification. The algorithm of this model is also elaborately described in Carpenter (1998).

The CPT model is expected to outperform the two competing models because of two reasons. First, the CPT, thanks specifically to the key feature of probability weighting, has proven fertile in explaining stock option subjective valuation patterns (Bahaji, 2011; Spalt, 2013), which makes it a promising candidate for analyzing the employee exercise behavior. Secondly, there exists empirical and experimental evidence on behavioral factors affecting employees exercise policies. Contrary to the normative framework, the CPT is expected to accurately capture these factors since it is a descriptive theory of the way people formulate their choices under risk and uncertainty.

The remainder of this section is organized as follows. Subsection 4.1 provides a description of the data and the construction of the variables used for this analysis. The models calibrations and the methodology used to assess their performances in predicting exercise patterns in the sample are presented in subsection 4.2. Subsection 4.3 discusses the results and draws some preliminary conclusions. The last subsection provides additional robustness analyses.

\subsection{Data set and construction of the variables}

\subsubsection{The data sample}

The data used in this research is a private data provided by a top-tier US actuary company. It includes extensive information on stock options exercises and cancellations for 12 US firms listed in the NYSE and the NASDAQ (6 of them are large caps). One of these firms was acquired in 2006, and consequently unlisted since then (see company F7 in table-1). As reported in table-1, the data set is about 542 stock option plans granted over the period from 1983 to 2006 to 7,125 employees ${ }^{8}$ located in 16 different countries. However, it is important to underline that $98 \%$ of the stock option holders are based in the USA. The plans expiration periods range from 5 to 10.5 years.

\footnotetext{
${ }^{8}$ The term "employee" is used to refer to all company insider labour categories, including executives as well as non executive employees.
} 
More specifically, the database includes details on individual grants characteristics, namely the employee ID, the plan ID, the number of granted options, the option strike price, the vesting schedule and the expiry date. It also comprises the following items regarding 35,086 individual exercise transactions related to these grants: the employee ID, the plan ID, the exercise date, the exercise stock price and the number of exercised options. In addition, the database contains individual information on options forfeitures, mainly including the forfeitures dates, the number of options forfeited and the related plan ID. In order to cover all the events of zero-payouts and cancellations, I identified all the plans that expired worthless (i.e. resulting in zero payout at maturity) using share price data from Bloomberg proprietary database. I then determined for each employee the number of outstanding options that ended in a zero payoff by crossing their granted plans IDs with the IDs of the plans identified in the previous step. I obtained a total number of 49,210 individual cancellation/expiry cases. The breakdown of this figure with respect to each firm is reported in table-1.

Recall that the focus of this research is the exercise patterns of standard employee stock options. Therefore, I dismissed from the dataset all the items related to specific grants whose vesting is contingent upon performance conditions. Actually, the initial dataset included 1,251 exercise transactions related to 7 performance stock option plans. All these specific plans were granted to top executives and senior managers. The 542 plans comprised in the scope of this study are Bermudianstyle stock option contracts with vesting schedules subject to service conditions. Some contracts are immediately vested (i.e. do not include vesting periods). The other contracts include either a cliff vesting or a gradual vesting. The vesting periods range from 2 to 9.5 years. All the contracts were granted almost at-the-money and do not comprise buyback provisions. Moreover, the options are not transferable and the beneficiaries are precluded, as insiders, from short selling the firm's stock according to section 16-c of the Securities Exchange Act. This prohibition stands for a hedging restriction.

As pointed out earlier, one of the strengths of this research is the quality of the dataset used. As far as I know, this research is one of the most comprehensive empirical studies on employee stock option exercise patterns in the American context.

\subsubsection{Construction of the variables}

The parameterization of the CPT model relies on two types of input variables. The first set of variables characterizes the exercise policy of the employee. The second set is specific to the economy of the stock option contracts. 
Table-1: Data sample characteristics

This table includes some descriptive information about the data sample. This sample includes 35,086 exercise transactions made by 7,125 employees in 12 US companies representing 9 different industries. It involves 542 stock option plans granted during the period from 1983 to 2006. The firms market capitalizations range from $\$ 323 \mathrm{M}$ to $\$ 40524 \mathrm{M}$ as at $12 / 31 / 2006$. The plans are standard stock option contracts (i.e. Bermudian-style options) that do not include performance-related vesting provisions. Their vesting is either immediate or achieved after specified periods varying from 2 to 9.5 years. The options maturities are from 5 to 10.5 years.

\begin{tabular}{|c|c|c|c|c|c|c|c|c|c|c|}
\hline Company & $\begin{array}{r}\text { Industry } \\
\text { (Sector) }\end{array}$ & $\begin{array}{c}\text { Market } \\
\text { Capitalization } \\
(*)\end{array}$ & $\begin{array}{c}\text { \# of } \\
\text { plans }\end{array}$ & $\begin{array}{l}\text { \# of exercise } \\
\text { transactions }\end{array}$ & $\begin{array}{c}\# \text { of } \\
\text { cancellations } \\
\text { and } \\
\text { expirations } \\
\end{array}$ & $\begin{array}{c}\text { Exercise } \\
\text { transactions } \\
\text { periods }\end{array}$ & $\begin{array}{l}\text { Grants } \\
\text { periods }\end{array}$ & $\begin{array}{l}\text { Vesting } \\
\text { periods }\end{array}$ & $\begin{array}{c}\text { \# of } \\
\text { involved } \\
\text { countries }\end{array}$ & $\begin{array}{c}\text { Options } \\
\text { terms }\end{array}$ \\
\hline $\mathrm{F} 1$ & $\begin{array}{l}\text { Financial } \\
\text { Guarantee } \\
\text { Insurance } \\
\end{array}$ & 1601 & 23 & 443 & 232 & $\begin{array}{l}02 / 1998 \text { to } \\
12 / 2005\end{array}$ & $\begin{array}{l}01 / 1997 \\
\text { to } \\
01 / 2003 \\
\end{array}$ & $\begin{array}{c}\text { Immediate, } \\
3 \text { and } 4 \\
\text { years }\end{array}$ & 4 & 7 years \\
\hline $\mathrm{F} 2$ & $\begin{array}{c}\text { Gas- } \\
\text { Distribution }\end{array}$ & 4275 & 86 & 1835 & 2079 & $\begin{array}{c}06 / 1995 \text { to } \\
03 / 2006\end{array}$ & $\begin{array}{c}02 / 1993 \\
\text { to } \\
11 / 2005\end{array}$ & 3 years & 1 & 10 years \\
\hline F3 & $\begin{array}{c}\text { Retail- } \\
\text { Discount }\end{array}$ & 40524 & 245 & 5740 & 11659 & $\begin{array}{l}03 / 1991 \text { to } \\
11 / 2005\end{array}$ & $\begin{array}{c}01 / 1999 \\
\text { to } \\
11 / 2000\end{array}$ & $\begin{array}{c}\text { Immediate } \\
\text { to } 9.5 \\
\text { years }\end{array}$ & 1 & 10 years \\
\hline $\mathrm{F} 4$ & $\begin{array}{l}\text { Retail-Drug } \\
\text { Store }\end{array}$ & 38898 & 5 & 6731 & 1281 & $\begin{array}{l}06 / 1994 \text { to } \\
06 / 2005\end{array}$ & $\begin{array}{c}10 / 1992 \\
\text { to } \\
10 / 1996\end{array}$ & 2 years & 1 & 10 years \\
\hline F5 & $\begin{array}{c}\text { Aerospace- } \\
\text { Defense }\end{array}$ & 12432 & 33 & 13981 & 11871 & $\begin{array}{c}05 / 1996 \text { to } \\
04 / 2006\end{array}$ & $\begin{array}{c}05 / 1995 \\
\text { to } \\
02 / 2005\end{array}$ & $\begin{array}{c}2 \text { and } 3 \\
\text { years }\end{array}$ & 1 & 10 years \\
\hline F6 & $\begin{array}{l}\text { Electric- } \\
\text { Integrated }\end{array}$ & 323 & 21 & 214 & 432 & $\begin{array}{l}05 / 2001 \text { to } \\
07 / 2005\end{array}$ & $\begin{array}{c}05 / 2000 \\
\text { to } \\
02 / 2004\end{array}$ & 3 years & 1 & 10 years \\
\hline F7 & $\begin{array}{c}\text { Pollution } \\
\text { Control }\end{array}$ & 8088 & 14 & 267 & 247 & $\begin{array}{l}06 / 2000 \text { to } \\
09 / 2005\end{array}$ & $\begin{array}{c}03 / 1997 \\
\text { to } \\
01 / 2004\end{array}$ & $\begin{array}{c}\text { Immediate, } \\
4 \text { and } 5 \\
\text { years }\end{array}$ & 1 & 10 years \\
\hline F8 & $\begin{array}{l}\text { Distribution- } \\
\text { Wholesale }\end{array}$ & 751 & 14 & 632 & 1025 & $\begin{array}{c}03 / 1996 \text { to } \\
09 / 2005\end{array}$ & $\begin{array}{c}03 / 1995 \\
\text { to } \\
04 / 2004\end{array}$ & $\begin{array}{l}\text { Immediate } \\
\text { to } 3 \text { yeas }\end{array}$ & 1 & $\begin{array}{c}5 \text { and } \\
10 \text { years }\end{array}$ \\
\hline F9 & $\begin{array}{c}\text { Gambling } \\
\text { (Non-Hotel) }\end{array}$ & 3030 & 22 & 474 & 862 & $\begin{array}{l}11 / 1993 \text { to } \\
03 / 2005\end{array}$ & $\begin{array}{c}02 / 1993 \\
\text { to } \\
10 / 2003\end{array}$ & $\begin{array}{c}\text { Immediate, } \\
4 \text { and } 5 \\
\text { years }\end{array}$ & 1 & 10 years \\
\hline F10 & $\begin{array}{l}\text { Instruments- } \\
\text { Controls }\end{array}$ & 10427 & 24 & 463 & 952 & $\begin{array}{l}06 / 1998 \text { to } \\
04 / 2005\end{array}$ & $\begin{array}{c}10 / 1996 \\
\text { to } \\
08 / 2003\end{array}$ & 5 years & 16 & $\begin{array}{c}6,10 \\
\text { and } \\
10.5 \\
\text { years }\end{array}$ \\
\hline F11 & $\begin{array}{l}\text { Property- } \\
\text { Casualty } \\
\text { Insurance }\end{array}$ & 1798 & 46 & 2624 & 2421 & $\begin{array}{l}03 / 1985 \text { to } \\
08 / 2005\end{array}$ & $\begin{array}{c}02 / 1983 \\
\text { to } \\
05 / 2004 \\
\end{array}$ & $\begin{array}{c}\text { Immediate, } \\
2,3 \text { and } 6 \\
\text { years }\end{array}$ & 1 & 10 years \\
\hline F12 & $\begin{array}{l}\text { Electric- } \\
\text { Integrated }\end{array}$ & 27512 & 9 & 1682 & 16149 & $\begin{array}{c}09 / 2004 \text { to } \\
02 / 2007\end{array}$ & $\begin{array}{c}02 / 2004 \\
\text { to } \\
02 / 2006\end{array}$ & $\begin{array}{c}\text { Immediate } \\
\text { and } 3 \\
\text { years }\end{array}$ & 1 & 10 years \\
\hline
\end{tabular}

(*) Market Capitalization at 12/31/2006 (in millions of \$), except for E7 (data at 07/06/2006 instead).

The first set of variables comprises the exercise stock price ratio and the cancellation rate. These variables are directly computed from the data sample described earlier. In particular, the cancellation rates were determined at the individual level (i.e. for each holder and for each plan), on an annual basis, as the number of the yearly forfeited and out-of-the money expired options divided by the total number of options granted with respect to a given plan. The final stock price levels were assimilated to the split-adjusted closing stock price at the expiration date normalized by the strike price. These ratios were computed using the data from the Bloomberg database. Note that for the specific case of the outstanding plans (representing roughly 11,750 exercise transactions), I used the closing share prices on October $29^{\text {th }} 2010$ as proxies for the final stock prices, except from the firm F7 for which the closing stock price as of July $6^{\text {th }} 2006$ was used instead. In addition, I must emphasize that, opposite to Carpenter (1998), average variables are not weighted by the sizes of exercise transactions because this 
conducts to introducing a bias in the variables estimates due to overweighting some exercise behaviors (i.e. employees with the largest stock option holdings) against others.

The second type of variables is mainly constructed based on financial data from the Bloomberg proprietary database, except from variables proper to the stock option contract design, namely the maturity dates and the vesting periods. These were drawn from the exercises data sample. Specifically, I used as a proxy of the risk free interest rate the prevailing US T-bills rates at the inception of each plan. Similar to Carpenter (1998), I used an equity risk premium of $7 \%$, which is roughly the arithmetic average premium over the period from 1958 to 2005 reported in Ibbotson Associates (2006). I computed the expected stock price return using the CAPM: the risk free rate plus the risk premium times the beta of the company at the grant date. The latter is computed against the relevant benchmark $^{9}$ using daily returns over the 1-year period prior to the grant date. In addition, dividend yields were estimated using recorded dividend data over the year prior to the exercise date. In the same manner, stock return volatilities were computed over the 360-day period prior to the exercise date.

Table-2 presents summary statistics on these variables. Panel-A exhibits descriptive statistics showing that, on average, the stock options vested after 1.80 years and were exercised after 4.30 years at stock prices representing 2.46 times the strike prices. Actually, average figures could be seen as variables describing exercise patterns in a representative company. Such a company would have then a volatility of $31.59 \%$, a $2.15 \%$ dividend yield, an expected stock return almost equal to $13 \%$ and an effective overall stock price performance equal to $111 \%$. Moreover, it is worth mentioning that the share price data covers the 2007-2008 crisis period, hence the maximum volatility of $94.03 \%$ and the minimum performance of $-99 \%$. These figures pertain to a financial company (F1). This company becomes a penny stock during the crisis period. Furthermore, the cancellation rates in the sample range from $0.00 \%$ to $28.57 \%$ with a mean of $6.30 \%$ which is lower than the mean cancellation rate in Carpenter (1998) equal to $7.30 \%$. Surprisingly, the median cancellation rate in the sample is identical to that in Bettis et al. (2005). On the other hand, the mean variables characterizing the stock option contract economy in Carpenter (1998) are noticeably close to ours. However, the variables describing exercise patterns in her sample show, by contrast, that exercises tend to occur latter (mean option lifetime of 5.83) at a higher stock price (mean exercise stock price ratio of 2.75).

Panel-B provides the cross-correlations of the variables. As expected, the correlations of the vesting period " $t_{v}$ " with the time to exercise " $\tau$ " and with the exercise price ratio " $S_{\tau}$ " are positive, which is consistent with the principle that options with longer vesting periods tend to be exercised later and deeper in the money. At the opposite, the exercises seem to occur latter and at higher stock price levels in the companies with lower dividend yields since both " $S_{\tau}$ " and " $\tau$ " are negatively

\footnotetext{
${ }^{9}$ Depending on the company listing stock exchange, betas were estimated either against the NYSE Composite index or the NASDAQ Composite index.
} 
correlated to " $q$ ". This is consistent with the American option rational exercise theory. Also, the volatility " $\sigma$ " is negatively correlated to the exercise time (while insignificantly correlated to the exercise price ratio) denoting an exercise behavior imbued with risk aversion (Huddart, 1994; Kulatilaka and Marcus, 1994; Carpenter, 1998).

\section{Table-2: Variables summary statistics}

This table reports summary statistics on the variables used in this empirical study. These include two types of variables: variables describing the exercise patterns and variables characterising the economy of the stock option contracts. The option exercise variables are constructed from a data sample of option exercises at 12 US companies. This set of variables includes the exercise stock price ratio " $S_{\tau}$ ", the lifetime of the option " $\tau$ ", the cancellation rate " $\eta$ " and the final stock price ratio " $S_{T}^{*}$ ". The variables specific to the economy of the stock option contract include the maturity of the option " $T$ ", the vesting period " $t$ ", the stock dividend yield " $q$ ", the stock price returns volatility " $\sigma$ ", the stock price Beta " $\beta$ ", the stock price expected return " $\mu$ " and the risk free rate " $r$ ".

\begin{tabular}{|c|ccccccccccc|}
\cline { 2 - 10 } \multicolumn{1}{c|}{} & $T$ & $S_{\tau}$ & $\tau$ & $t_{v}$ & $q$ & $\sigma$ & $S_{T}^{*}$ & $\beta$ & $r$ & $\mu$ & $\eta$ \\
\hline Panel A: Descriptive statistics & & & & & & & & & & \\
Maximum & 10.50 & 49.39 & 10.01 & 9.50 & $9.94 \%$ & $94.03 \%$ & 51.57 & 1.12 & $7.00 \%$ & $14.41 \%$ & $28.57 \%$ \\
Minimum & 5.00 & 1.01 & 0.06 & 0.00 & $0.00 \%$ & $12.46 \%$ & 0.01 & 0.40 & $4.44 \%$ & $7.25 \%$ & $0.00 \%$ \\
Average & 9.90 & 2.46 & 4.30 & 1.80 & $2.15 \%$ & $31.59 \%$ & 2.11 & 0.80 & $5.50 \%$ & $12.59 \%$ & $6.30 \%$ \\
Median & 10.00 & 1.66 & 3.63 & 2.00 & $1.36 \%$ & $29.93 \%$ & 1.38 & 0.80 & $5.35 \%$ & $11.52 \%$ & $4.11 \%$ \\
Standard deviation & 0.66 & 1.96 & 2.46 & 0.72 & 0.02 & $10.82 \%$ & 3.17 & 0.24 & $0.81 \%$ & $2.18 \%$ & $24.30 \%$ \\
Q1 (average) & 9.95 & 1.89 & 5.43 & 2.21 & $2.29 \%$ & $19.78 \%$ & 1.45 & 0.61 & $5.40 \%$ & $8.41 \%$ & $11.09 \%$ \\
Q3 (average) & 9.90 & 2.38 & 4.12 & 1.99 & $1.49 \%$ & $29.51 \%$ & 2.50 & 0.79 & $5.61 \%$ & $12.54 \%$ & $7.70 \%$ \\
Q5 (average) & 9.95 & 2.31 & 3.21 & 2.24 & $1.74 \%$ & $48.78 \%$ & 1.94 & 1.29 & $5.34 \%$ & $15.20 \%$ & $11.76 \%$ \\
\hline Panel B: Correlations & & & & & & & & & & & \\
$T$ & 1.000 & & & & & & & & & & \\
$S_{\tau}$ & 0.075 & 1.000 & & & & & & & & & \\
$\tau$ & 0.025 & 0.504 & 1.000 & & & & & & & & \\
\hline & -0.084 & 0.147 & 0.303 & 1.000 & & & & & & & \\
\hline
\end{tabular}

\subsection{The methodology}

\subsubsection{Models calibration}

If the subjective values of the stock options where observable, one would estimate the preferences parameters implied by these values (i.e. choose the parameters that make the option values yielded by the model best match observed prices). Instead, I calibrated each model to best match the values of the variables characterizing the exercise behavior, namely the exercise price ratio and the cancellation rate. Following Carpenter (1998), I started by performing a base case calibration consisting in finding the set of unknown parameters " $P$ " that makes the models predictions best fit the average values of the observed exercise variables (i.e. fit a representative company whose variables are equal to the sample mean values). In order to check the accuracy of the base case calibrations under which the models will be compared, I performed some alternative calibrations for the CPT model and the EU model. All the calibrations are performed based on a two-month time-step setting.

\subsubsection{The CPT model}


For the CPT model, the set of the unknown parameters that need to be estimated is " $P=\left\{a, \rho, p_{e}, y\right\}$ ". Some of these parameters, namely " $a$ " and " $\rho$ ", describe the preferences of a representative employee. The other parameters characterizing his risk preferences (i.e. the value function curvature and the loss aversion parameters) are set at their experimental estimates from the CPT (Tversky and Kahneman, 1992): “ $\hat{\lambda}=2.25$ " and " $\hat{\alpha}=0.88$ ". I used the methodology in Carpenter (1998) that consists in the minimization of a cost function " $\varepsilon\left(a, \rho, p_{e}, y\right)$ " measuring the distance between mean observations and the model predictions. As we can notice from the following optimization problem, the function gives more weight to the variable that has less cross-sectional dispersion:

$$
\begin{aligned}
& P=\underset{a, \rho, p_{e}, y}{\operatorname{ArgMin}} \varepsilon\left(a, \rho, p_{e}, y\right) \\
& \varepsilon\left(a, \rho, p_{e}, y\right)=\frac{\left(\bar{S}_{\tau}-\hat{S}_{\tau}\left(a, \rho, p_{e}, y\right)\right)^{2}}{\sigma_{S_{\tau}}{ }^{2}}+\frac{\left(\bar{\eta}-\hat{\eta}\left(a, \rho, p_{e}, y\right)\right)^{2}}{\sigma_{\eta}{ }^{2}}
\end{aligned}
$$

where the hats represent the model predictions, the bars are the sample averages and the denominators are their sample variances.

Panel-1 of table-3 exhibits the parameters estimates ${ }^{10}$ yielded by the base case calibration of the CPT model. According to the $\chi^{2}$-test, the calibration error is statistically insignificant at the $1 \%$ level, which means that the calibration results are statistically significant. The results show that the representative employee would set the reference point quite high at a level equivalent to an annual share price performance of $22 \%$. Moreover, there is a $4 \%$ probability for him to leave the company for a cash amount of $\$ 0.23$ per each option held. This amount represents almost $60 \%$ of the BS value of the option granted to him $(\$ 0.41)$. Another interesting result yielded by the base case calibration is the probability weighting parameter estimate $(\hat{a}=0.69)$ that lies within the range of the experimental estimates $^{11}$. Actually, the experimental literature shows that this parameter may range from 0.56 to 0.71 with an average value of roughly 0.65 . In addition, this result is consistent with Polkovnichenko and Zhao (2013) finding that the Kahneman and Tversky probability weighting function parameter implied by S\&P options prices is close to 0.7 during the periods when they found empirical support for

\footnotetext{
${ }^{10}$ The optimization problem was solved numerically based on a Monte Carlo approach. This method consists in randomly drawing values of the parameters within their definition domains. The drawn values are saved if they yield lower error value than the previous one. This process is retrieved until either the error threshold is hit or the maximum number of trials is achieved. The error threshold and the number of trials used are respectively $10^{-5}$ and 10,000 .

${ }^{11}$ Tversky and Kahneman (1992) got 0.65 on average ( " $a=0.61$ " for gains and " $b=0.69$ " for losses). These results are corroborated by Abdellaoui's (2000) findings ( " $a=0.60$ " for gains and " $b=0.70$ " for losses, hence an average of 0.65). In addition, Camerer and Ho (1994) obtained " $a=0.56$ " for gains whereas Gonzales and Wu (1996) and Bleichrodt and Pinto (2000) found " $a=0.71$ " and " $a=0.67$ " respectively.
} 
the inverse S-shaped probability weighting function (i.e. weighting function emphasizing risk in the tails of a distribution). Furthermore, this probability weighting evidence could be potentially denoting an overconfidence behavior in the sense that overconfident employees would be more optimistic than rational individuals about future prospects. Therefore, they are more likely to overweight low probabilities of large positive outcomes. It follows that the overconfidence bias would drive them to delay the exercise of their stock options. The outlined finding here is broadly consistent with some researches using options exercise timing as a proxy of executive overconfidence. For instance, Malmendier and Tate $(2005,2008)$ classified CEOs as overconfident when, in spite of their lack of diversification, they hold their stock-options until expiry.

Panel-1 also includes the results of two alternative calibrations. The purpose of the alternative calibration \#1 is to estimate a variant of the model excluding the non-market factors. It relies on the neutralization of the effect of the exit probability, by setting it at zero, and then the calibration of the model for all the other parameters. The set of parameters that need to be estimated in this case becomes " $P=\{a, \rho, \lambda, \alpha\}$ ". The alternative \#2 aims to check the robustness of the base case calibration with respect to the probability weighting parameter. It consists in setting the latter at the average experimental estimate of 0.65 and then estimating the remaining free parameters. As we can see from the $\chi^{2}$-test $p$-values in panel-1, both alternatives are statistically significant at the $1 \%$ level. They also turn out to have comparable errors to that of the base case calibration. The results yielded by the alternative calibration \#1 show that the sole factors representing the CPT preferences could be sufficient to explain average exercise patterns. The estimates of loss aversion and the value function curvature parameter are still close to the CPT experimental estimates. However, given that the probability weighting parameter " $a$ " estimate implied by this calibration is close to 1 (i.e. extremely weak probability weighting effect), inconsistently, this beliefs feature turns out to be irrelevant with regards to the exercise behavior patterns in the absence of the non-market factors. It is also worth noticing that the results from the alternative \#2 show that setting this parameter at the mean experimental estimate is neutral to the performance of the calibration and does not affect significantly the estimates of the other parameters. In summary, these results, along with the remark that the model predictions are quite steady across all the calibrations, plead in favor of the robustness of the base case calibration.

In addition to this robustness check, I examined the effect of the share price volatility on the calibration outcomes. This analysis consists in estimating the model parameters based on the average data reassessed from the first (Q1) the middle (Q3) and the last (Q5) quintiles of the sample sorted with respect to the share price volatility (see table-2). As we can see from the figures reported in panel-1 of table-3, all the calibrations are significant, at the $10 \%$ level at most. The probability weighting parameter estimates are stable around 0.66, which remains comparable to the experimental estimates. Further, the value of the exit probability " $p_{e}$ " increases at the top quintile (Q5) importantly. 
This intuitively interprets as follows: the exercise behavior of an employee working for a risky company indicates that he is much more likely to quit and, therefore, bears a higher risk of giving up his stock options holding. This interpretation is consistent, on the other hand, with the result that such an employee will require a noticeably higher compensation amount to leave his job. Based on the estimate yielded by the Q5 calibration, this amount evaluates to 7 times the BS value of the average contract of this quintile (\$0.54). Note though that, interestingly, even the expected leaving amount in this case $(\$ 3.80 \times 0.21=\$ 0.80)$ is far greater than the BS value. Another interesting finding is that the reference point increases with the stock price volatility. This means that, on average, stock option holders would be more conservative about the gains and losses breakeven within a volatile/risky decision making environment.

\subsubsection{The EU model}

I used the same methodology to calibrate the EU model. The optimization problem in the base case calibration is described by the set of equations in (10). The numerical resolution of this problem leads to estimating the set of the unknown parameters " $P=\left\{w, p_{e}, y\right\}$ ". Similar to Carpenter (1998) and Bettis et al. (2005), I set the risk aversion coefficient to 2 .

$$
\begin{aligned}
& P=\underset{w, p_{e}, y}{\operatorname{ArgMin}} \mathcal{E}\left(w, p_{e}, y\right) \\
& \varepsilon\left(w, p_{e}, y\right)=\frac{\left(\bar{S}_{\tau}-\hat{S}_{\tau}\left(w, p_{e}, y\right)\right)^{2}}{\sigma_{S_{\tau}}{ }^{2}}+\frac{\left(\bar{\eta}-\hat{\eta}\left(w, p_{e}, y\right)\right)^{2}}{\sigma_{\eta}{ }^{2}}
\end{aligned}
$$

The results of the base case calibration are reported in panel-2 of table-3. As we can see from the $\chi^{2}$-test $p$-value, this calibration is significant at the $1 \%$ level. The parameters estimates imply that the representative employee outside wealth would have to be slightly less than 7 times the value of the stock. These results also suggest that the employee would have a 5\% chance to leave the company and receive an amount of $\$ 0.28$ per granted option, which is consistent with the estimates from the CPT model base case calibration.

Panel-2 also reports the results of an alternative calibration. Similar to that in the CPT model, this alternative aims to calibrate a version that is neutral to the non-market factors in order to assess the ability of the sole preferences framework to fit the mean exercise data. The set of parameters that needs to be estimated under this calibration becomes then " $P=\{\gamma, w\}$ ". The yielded calibration error is insignificant at the $1 \%$ level and is close to that implied by the calibration of the CPT model equivalent specification (i.e. disregarding the non-market factors). The parameters estimates show that, in case there is no chance for the representative employee to quit the company, his risk-aversion 
would have to be slightly higher than the level assumed under the base case calibration $(\hat{\gamma}=2.80)$ while his non-option wealth estimate remains almost the same.

The volatility effect on the parameters estimates is depicted through the quintiles analysis, also reported in panel-2. This analysis shows that the exit probability and the expected leaving amount estimates are significantly higher in the upper volatility quintile (Q5), which is consistent with the argument drawn from the CPT model calibration results that risky firms stock option holders are more likely to quit and, therefore, require a higher expected exit amount in order to compensate the losses of their forfeited stock options.

\subsubsection{The EA model}

The parameter of interest for the calibration of the EA model is the exit probability, thus " $P=\left\{p_{e}\right\}$ ". In the same way as previously done, the calibration process relies on the following optimization problem:

$$
\begin{aligned}
& P=\underset{p_{e}}{\operatorname{ArgMin}} \varepsilon\left(p_{e}\right) \\
& \varepsilon\left(p_{e}\right)=\frac{\left(\bar{S}_{\tau}-\hat{S}_{\tau}\left(p_{e}\right)\right)^{2}}{\sigma_{S_{\tau}}{ }^{2}}+\frac{\left(\bar{\eta}-\hat{\eta}\left(p_{e}\right)\right)^{2}}{\sigma_{\eta}{ }^{2}}
\end{aligned}
$$

As we can see from the calibration results reported in panel-3 of table-3, the calibration is significant at the $1 \%$ level and yields an exit probability estimate consistent with those implied by the two previous models. Note also that the exit probability estimate at the upper volatility quintile is supportive of the finding from the CPT model that risky firms employees are more likely to exit and, consequently, are more subject to stock options forfeiture risk.

\subsubsection{The criteria of the models comparison}

In order to compare the ability of the models to predict exercise patterns in the sample based on their respective base case calibrations, I computed the models forecasts of the exercise stock price ratio for each of the 35,086 exercise transactions in the sample. Beyond the information implied by the base case calibrations (i.e. embedded in the preferences parameters), these forecasts integrate specific information about the exercised stock options and the prevailing market conditions, namely the vesting period, the maturity date, the expected stock price return, the stock price volatility, the dividend yield, the risk free rate and the final stock price level. Consistent with the calibrations setting, the computations were performed using two-month time steps. Formally, for a given transaction " $i$ ", with $i \in\{1 ; 2 ; \ldots ; 35,086\}$, the related predictions are assimilated to the following conditional expectations: 


$$
\hat{S}_{\tau, i}=I E^{p}\left(S_{\tau, i} / P, t_{v, i}, T_{i}, \mu_{i}, \sigma_{i}, q_{i}, r_{i}, s_{T, i}^{*}\right)
$$

\section{Table-3: The calibration results}

This table presents the results of the calibrations of the three competing models. Panel-1 exhibits figures specific to the calibration of the CPT model. Panel-2 and Panel-3 report the results of the calibration of the EU model and the EA model respectively. The upper block of each panel includes the parameters estimates yielded by of the calibrations. The middle block comprises the calibrations errors " $\varepsilon$ " and the related $x^{2}$ significance test $\mathrm{p}$-values where the null hypothesis is "H0: $\varepsilon \neq 0$ ". The bottom block reports the model forecasts of the exercise variables implied by each calibration, including the expected cancellation rate and the conditional expectations of the stock price exercise ratios and the exercise timing. A “*”, “**” or “***” indicates significance at the $10 \%, 5 \%$ or $1 \%$ level, respectively.

\begin{tabular}{|c|c|c|c|c|c|c|}
\hline Calibration outputs & $\begin{array}{c}\text { Base case } \\
\text { calibration }\end{array}$ & Q1 & Q3 & Q5 & $\begin{array}{c}\text { Alternative } \\
\# 1\end{array}$ & $\begin{array}{c}\text { Alternative } \\
\# 2\end{array}$ \\
\hline \multicolumn{7}{|l|}{ Panel-1: CPT Model } \\
\hline$\hat{p}_{e}$ & 0.04 & 0.04 & 0.04 & 0.21 & - & 0.04 \\
\hline$\hat{\rho}$ & $22 \%$ & $17 \%$ & $20 \%$ & $30 \%$ & $25 \%$ & $22 \%$ \\
\hline$\hat{y}$ & 0.23 & 0.95 & 0.90 & 3.80 & - & 0.22 \\
\hline$\hat{a}$ & 0.69 & 0.64 & 0.68 & 0.66 & 0.96 & 0.65 \\
\hline$\hat{\lambda}$ & 2.25 & 2.25 & 2.25 & 2.25 & 2.17 & 2.25 \\
\hline$\hat{\alpha}$ & 0.88 & 0.88 & 0.88 & 0.88 & 0.83 & 0.88 \\
\hline Calibration error: $\varepsilon(a, \rho, q, y)$ & $0.0012 * * *$ & $0.1192 *$ & $0.0167 * * *$ & $0.0230 * *$ & $0.0022 * * *$ & $0.001 * * *$ \\
\hline$N^{2}$ test ( $p$-value $)$ & 0.001 & 0.058 & 0.009 & 0.012 & 0.002 & 0.001 \\
\hline$\hat{\hat{S}_{\tau}}$ & 2.46 & 1.60 & 2.29 & 2.31 & 2.46 & 2.46 \\
\hline$\hat{\tau}$ & 6.46 & 7.41 & 6.34 & 4.50 & 5.76 & 6.48 \\
\hline$\hat{\eta}$ & $5.47 \%$ & $4.57 \%$ & $5.50 \%$ & $8.31 \%$ & $5.16 \%$ & $5.45 \%$ \\
\hline \multicolumn{7}{|l|}{ Panel-2: EU Model } \\
\hline$\hat{\gamma}$ & 2.00 & 2.00 & 2.00 & 2.00 & 2.90 & \\
\hline$\hat{w}$ & 7.80 & 0.46 & 5.30 & 0.46 & 7.78 & \\
\hline$\hat{p}_{e}$ & 0.05 & 0.08 & 0.08 & 0.16 & - & \\
\hline$\hat{y}$ & 0.28 & 0.20 & 0.34 & 0.20 & - & \\
\hline Calibration error: $\varepsilon(\gamma, w, q, y)$ & $0.0008^{* * *}$ & $0.1013^{* *}$ & $0.0153^{* * *}$ & $0.0857 * *$ & $0.0020^{* * *}$ & \\
\hline $\mathrm{N}^{2}$ test $(p$-value $)$ & 0.000 & 0.049 & 0.008 & 0.042 & 0.001 & \\
\hline$\hat{\hat{S}_{\tau}}$ & 2.47 & 1.67 & 2.46 & 2.10 & 2.46 & \\
\hline$\hat{\tau}$ & 6.78 & 7.05 & 6.57 & 4.17 & 6.30 & \\
\hline$\hat{\eta}$ & $5.62 \%$ & $4.56 \%$ & $5.03 \%$ & $7.24 \%$ & $5.21 \%$ & \\
\hline \multicolumn{7}{|l|}{ Panel-3: EA Model } \\
\hline$\hat{p}_{e}$ & 0.06 & 0.05 & 0.06 & 0.50 & & \\
\hline Calibration error: $\varepsilon(q)$ & $0.0044^{* * *}$ & $0.0753^{* *}$ & $0.0119^{* * *}$ & 0.3780 & & \\
\hline$\aleph^{2}$ test $(p$-value $)$ & 0.003 & 0.041 & 0.006 & 0.172 & & \\
\hline$\hat{\hat{S}_{\tau}}$ & 2.33 & 1.80 & 2.48 & 2.08 & & \\
\hline$\hat{\tau}$ & 6.24 & 6.80 & 6.64 & 4.64 & & \\
\hline$\hat{\eta}$ & $6.03 \%$ & $4.75 \%$ & $5.53 \%$ & $9.18 \%$ & & \\
\hline
\end{tabular}

Further, to assess the performance of each model in explaining the cross-sectional variations in the exercise variable, I used the following metrics:

- Mean Absolute Percentage Errors (MAPE):

$\xi_{s}=\frac{1}{n} \sum_{i=1}^{n} \frac{\left|S_{\tau, i}-\hat{S}_{\tau, i}\right|}{\hat{S}_{\tau, i}}$ 
- $\quad$ Mean Squared Percentage Errors (MSPE):

$\varepsilon_{s}=\frac{1}{n} \sum_{i=1}^{n}\left[\frac{\left(S_{\tau, i}-\hat{S}_{\tau, i}\right)}{\hat{S}_{\tau, i}}\right]^{2}$

Where $n$ is the size of the sample.

Recall that the MSPE metric aims to penalize the forecast errors that are higher than 1 and to favor those blow.

- The following OLS regression:

$S_{\tau, i}=\alpha_{s}+\beta_{s} \hat{S}_{\tau, i}+\tilde{z}_{s, i}$

The most performing model should have the lowest MSPE and/or MAPE and the most consistent regression adjustment (i.e. the highest $\mathrm{R}^{2}$ with a consistent slope estimate). In order to check whether the spreads between the metrics yielded by each model are statistically significant, I used the impaired Student's t-test.

I reiterated the same approach to compare the performance of the models based on their middle quintile calibrations (column Q3 of table-3)..The purpose of this piece of the analysis is to provide an out-of-sample assessment of the models predictive performances controlling for the risk degree of the exercise decision environment. It therefore uses the data subsample excluding the middle quintile. The number of exercise transactions comprising this sample reduces then to 28,069 .

\subsection{The results}

Table-4 summaries the results of the in-sample analysis. These results are reported within two blocks. The left-hand block includes the forecast errors metrics (i.e. MSPE and MAPE) and the related p-values. The right-hand block contains the OLS regression statistics including the adjusted $\mathrm{R}^{2}$ and the intercept " $\beta_{s}$ ".

Panel-1 figures are about the analysis based on the broad sample. Consistent with the hypothesis stated earlier, the CPT model outperforms the two competing models since it yields forecast errors below the smallest of any of the forecast errors yielded by the other models. The differences between all forecast errors mean values are significant at the $1 \%$ level. In addition, the CPT model has the highest $\mathrm{R}^{2}$ and its regression slope is significantly positive at the $1 \%$ level. Therefore relying on the base case calibrations, the CPT model shows some improvements over the EU model and the EA model in terms of both the size of the forecast errors and the variance explanatory power of the OLS regression. Further, the EA model turns out to be the worst performing model under the base case 
calibration, even when compared to the EU model. In fact, the differences between the forecast errors of the two models are meaningful in that the t-test is significant at the $1 \%$ level. This finding contrasts to the results in Carpenter (1998) showing that the EU model performs as well as the EA model. It is consistent however with Bettis et al. (2005) finding that, compared to the EU model, the EA model produces exercise behavior forecasts that are further away from the observed values.

The subsequent panels report the results of the analysis based on the subsamples representing the sample quintiles with respect to the stock price volatility. The purpose here is to verify that the performance of the CPT model is not significantly concentrated in a specific cluster of the sample. If it turns to be the case, then the previous results may suffer a contingency bias raised by the exercise decision environment risk level. As we can notice, the average forecast errors are the highest at the lower volatility quintiles. This means that the predictive performance of the models is poor in a low risk decision making environment. This is also supported by the OLS analysis in that the linear adjustment results are not satisfactory at the lowest quintiles. At the bottom quintile for instance, the regression slopes are even negative. Moreover, the CPT model yields the lowest average forecast errors. The spreads relative to the average forecast errors implied by the other models are statistically significant, except at the $4^{\text {th }}$ quintile where all the models perform mostly comparably. Furthermore, relying on the OLS analysis, the CPT model shows the most consistent results compared to the other models in the sense that its yielded expected exercise ratios are positively linked to those from the subsamples, in spite of the $\mathrm{R}^{2}$ being too low at the second quintile and at the top quintile.

Table-5 provides the results of the out-of-sample empirical analysis. The figures exhibited in panel-1 denote a perceptible decline in the average forecast errors yielded by the models, while confirming the overperformance of the CPT model. The quintiles breakdown of the models predictive performances leads to conclusions similar to those drawn from the in-sample analysis. It shows though that the deterioration of the models MSPE is mainly concentrated at the $2^{\text {nd }}$ and the $4^{\text {th }}$ quintiles. The results of the OLS regression are not noticeably different from those of the in-sample analysis as well and, therefore, do not deserve further comments.

In essence, the CPT model shows a substantial improvement over the EU model and the EA model in terms of the size of the average forecast errors. It also achieves some slight improvements in linearly adjusting the empirical exercise ratios. Therefore, the CPT framework turns out to be the best candidate in explaining the exercise decisions in the data sample. 


\section{Table-4: Models in-sample comparison}

This table presents the results of the in-sample comparison of the models based on their base case calibrations. Mean variable of interest in this analysis is the exercise stock price ratio. The forecasting performance of each model is assessed based on the Mean Squared Percentage Error (MSPE), the Mean Absolute Percentage Error (MAPE) and the outputs of the OLS regression of the variables observed values over the models predictions. The meaningfulness of the differences between the forecast errors metrics is formally tested across the models using the impaired unilateral Student's t-test. The first panel reports the results of the OLS regression and the values of the forecast errors metrics for the whole sample. In the subsequent panels similar outputs are reported but focusing on 5 subsamples representing each a sample quintile with respect to the stock price volatility. P-values are in parentheses.

\begin{tabular}{|c|c|c|c|c|c|c|c|c|c|c|c|c|}
\hline \multirow{3}{*}{$\begin{array}{c}\text { Models } \\
\text { comparisons }\end{array}$} & \multicolumn{6}{|c|}{ Forecast Errors Statistics } & \multicolumn{6}{|c|}{ OLS analysis } \\
\hline & \multicolumn{3}{|c|}{ MSPE } & \multicolumn{3}{|c|}{ MAPE } & \multicolumn{2}{|c|}{ CPT } & \multicolumn{2}{|c|}{ EU } & \multicolumn{2}{|c|}{ EA } \\
\hline & $C P T$ & $E U$ & $E A$ & $C P T$ & $E U$ & $E A$ & $B$ & $R^{2}$ & $\beta$ & $R^{2}$ & $\beta$ & $R^{2}$ \\
\hline $\begin{array}{l}\text { Panel-1: Overall } \\
\text { t-test against EU } \\
\text { t-test against EA }\end{array}$ & $\begin{array}{l}1.065 \\
(0.000) \\
(0.000)\end{array}$ & $\begin{array}{l}1.249 \\
(0.000)\end{array}$ & 1.408 & $\begin{array}{l}0.589 \\
(0.000) \\
(0.000)\end{array}$ & $\begin{array}{l}0.627 \\
(0.014)\end{array}$ & 0.643 & $\begin{array}{l}0.381 \\
(0.000)\end{array}$ & 0.15 & $\begin{array}{l}0.176 \\
(0.000)\end{array}$ & 0.07 & $\begin{array}{l}0.375 \\
(0.000)\end{array}$ & 0.10 \\
\hline $\begin{array}{l}\text { Panel-2: Q1 } \\
\text { t-test against EU } \\
\text { t-test against EA }\end{array}$ & $\begin{array}{l}0.886 \\
(0.000) \\
(0.038)\end{array}$ & $\begin{array}{l}1.026 \\
(0.004)\end{array}$ & 0.941 & $\begin{array}{l}0.450 \\
(0.169) \\
(0.131)\end{array}$ & $\begin{array}{l}0.464 \\
(0.405)\end{array}$ & 0.461 & $\begin{array}{r}-0.152 \\
(0.000)\end{array}$ & 0.02 & $\begin{array}{r}-0.499 \\
(0.000)\end{array}$ & 0.06 & $\begin{array}{r}-0.329 \\
(0.000)\end{array}$ & 0.04 \\
\hline $\begin{array}{l}\text { Panel-3: Q2 } \\
\text { t-test against EU } \\
\text { t-test against EA }\end{array}$ & $\begin{array}{l}3.584 \\
(0.000) \\
(0.000)\end{array}$ & $\begin{array}{l}4.290 \\
(0.000)\end{array}$ & 4.991 & $\begin{array}{l}1.359 \\
(0.000) \\
(0.000)\end{array}$ & $\begin{array}{l}1.466 \\
(0.000)\end{array}$ & 1.583 & $\begin{array}{l}0.800 \\
(0.001)\end{array}$ & 0.03 & $\begin{array}{c}-3.184 \\
(0.000)\end{array}$ & 0.17 & $\begin{array}{l}-8.678 \\
(0.000)\end{array}$ & 0.41 \\
\hline $\begin{array}{l}\text { Panel-4: Q3 } \\
\text { t-test against EU } \\
\text { t-test against EA }\end{array}$ & $\begin{array}{l}0.439 \\
(0.025) \\
(0.000)\end{array}$ & $\begin{array}{l}0.483 \\
(0.000)\end{array}$ & 0.597 & $\begin{array}{l}0.434 \\
(0.003) \\
(0.000)\end{array}$ & $\begin{array}{l}0.458 \\
(0.001)\end{array}$ & 0.489 & $\begin{array}{l}0.485 \\
(0.000)\end{array}$ & 0.22 & $\begin{array}{l}0.373 \\
(0.000)\end{array}$ & 0.15 & $\begin{array}{c}-0.139 \\
(0.002)\end{array}$ & 0.03 \\
\hline $\begin{array}{l}\text { Panel-5: Q4 } \\
\text { t-test against EU } \\
\text { t-test against EA }\end{array}$ & $\begin{array}{l}0.255 \\
(0.356) \\
(0.222)\end{array}$ & $\begin{array}{l}0.285 \\
(0.685)\end{array}$ & 0.330 & $\begin{array}{l}0.347 \\
(0.000) \\
(0.000)\end{array}$ & $\begin{array}{l}0.375 \\
(0.000)\end{array}$ & 0.309 & $\begin{array}{l}1.517 \\
(0.000)\end{array}$ & 0.65 & $\begin{array}{l}1.580 \\
(0.000)\end{array}$ & 0.62 & $\begin{array}{l}2.155 \\
(0.000)\end{array}$ & 0.68 \\
\hline $\begin{array}{l}\text { Panel-6: Q5 } \\
\text { t-test against EU } \\
\text { t-test against EA }\end{array}$ & $\begin{array}{l}0.167 \\
(0.059) \\
(0.094)\end{array}$ & $\begin{array}{l}0.184 \\
(0.597)\end{array}$ & 0.188 & $\begin{array}{l}0.354 \\
(0.000) \\
(0.000)\end{array}$ & $\begin{array}{l}0.374 \\
(0.632)\end{array}$ & 0.373 & $\begin{array}{l}0.111 \\
(0.000)\end{array}$ & 0.06 & $\begin{array}{c}-0.118 \\
(0.000)\end{array}$ & 0.07 & $\begin{array}{l}0.074 \\
(0.000)\end{array}$ & 0.04 \\
\hline
\end{tabular}

\section{Table-5: Models out-of-sample comparison}

This table presents the results of the out-of-sample comparison of the models based on their middle quintile (Q3) calibrations. Mean variable of interest in this analysis is the exercise stock price ratio. The forecasting performance of each model is assessed based on the Mean Squared Percentage Error (MSPE), the Mean Absolute Percentage Error (MAPE) and the outputs of the OLS regression of the variables observed values over the models predictions. The meaningfulness of the differences between the forecast errors metrics is formally tested across the models using the impaired unilateral Student's t-test. The first panel reports the results of the OLS regression and the values of the forecast errors metrics for the whole sample. In the subsequent panels similar outputs are reported but focusing on 5 subsamples representing each a sample quintile with respect to the stock price volatility. P-values are in parentheses.

\begin{tabular}{|c|c|c|c|c|c|c|c|c|c|c|c|c|}
\hline \multirow{3}{*}{$\begin{array}{c}\text { Models } \\
\text { comparisons }\end{array}$} & \multicolumn{6}{|c|}{ Forecast Errors Statistics } & \multicolumn{6}{|c|}{ OLS analysis } \\
\hline & \multicolumn{3}{|c|}{ MSPE } & \multicolumn{3}{|c|}{ MAPE } & \multicolumn{2}{|c|}{ CPT } & \multicolumn{2}{|c|}{ EU } & \multicolumn{2}{|c|}{ EA } \\
\hline & $C P T$ & $E U$ & $E A$ & $C P T$ & $E U$ & $E A$ & $B$ & $R^{2}$ & $\beta$ & $R^{2}$ & $\beta$ & $R^{2}$ \\
\hline $\begin{array}{l}\text { Panel-1: Overall } \\
\text { t-test against EU } \\
\text { t-test against EA }\end{array}$ & $\begin{array}{l}1.304 \\
(0.000) \\
(0.000)\end{array}$ & $\begin{array}{l}1.526 \\
(0.000)\end{array}$ & 1.583 & $\begin{array}{l}0.629 \\
(0.000) \\
(0.000)\end{array}$ & $\begin{array}{l}0.675 \\
(0.441)\end{array}$ & 0.676 & $\begin{array}{l}0.530 \\
(0.000)\end{array}$ & 0.16 & $\begin{array}{l}0.196 \\
(0.000)\end{array}$ & 0.07 & $\begin{array}{l}0.465 \\
(0.000)\end{array}$ & 0.13 \\
\hline $\begin{array}{l}\text { Panel-2: Q1 } \\
\text { t-test against EU } \\
\text { t-test against EA }\end{array}$ & $\begin{array}{l}0.880 \\
(0.000) \\
(0.026)\end{array}$ & $\begin{array}{l}1.039 \\
(0.001)\end{array}$ & 0.940 & $\begin{array}{l}0.450 \\
(0.455) \\
(0.262)\end{array}$ & $\begin{array}{l}0.448 \\
(0.237)\end{array}$ & 0.459 & $\begin{array}{r}-0.197 \\
(0.038)\end{array}$ & 0.02 & $\begin{array}{r}-0.205 \\
(0.098)\end{array}$ & 0.02 & $\begin{array}{r}-0.366 \\
(0.000)\end{array}$ & 0.05 \\
\hline $\begin{array}{l}\text { Panel-3: Q2 } \\
\text { t-test against EU } \\
\text { t-test against EA }\end{array}$ & $\begin{array}{l}3.833 \\
(0.000) \\
(0.000)\end{array}$ & $\begin{array}{l}4.549 \\
(0.000)\end{array}$ & 4.873 & $\begin{array}{l}1.398 \\
(0.000) \\
(0.000)\end{array}$ & $\begin{array}{l}1.515 \\
(0.030)\end{array}$ & 1.563 & $\begin{array}{l}0.183 \\
(0.546)\end{array}$ & 0.01 & $\begin{array}{c}-4.472 \\
(0.000)\end{array}$ & 0.19 & $\begin{array}{l}-7.147 \\
(0.000)\end{array}$ & 0.34 \\
\hline $\begin{array}{l}\text { Panel-5: Q4 } \\
\text { t-test against EU } \\
\text { t-test against EA }\end{array}$ & $\begin{array}{l}0.357 \\
(0.440) \\
(0.408)\end{array}$ & $\begin{array}{l}0.342 \\
(0.461)\end{array}$ & 0.332 & $\begin{array}{l}0.339 \\
(0.000) \\
(0.000)\end{array}$ & $\begin{array}{l}0.372 \\
(0.000)\end{array}$ & 0.308 & $\begin{array}{l}1.870 \\
(0.000)\end{array}$ & 0.65 & $\begin{array}{l}1.877 \\
(0.000)\end{array}$ & 0.63 & $\begin{array}{l}2.156 \\
(0.000)\end{array}$ & 0.69 \\
\hline $\begin{array}{l}\text { Panel-6: Q5 } \\
\text { t-test against EU } \\
\text { t-test against EA }\end{array}$ & $\begin{array}{l}0.146 \\
(0.030) \\
(0.008)\end{array}$ & $\begin{array}{l}0.173 \\
(0.190)\end{array}$ & 0.188 & $\begin{array}{l}0.327 \\
(0.000) \\
(0.000)\end{array}$ & $\begin{array}{l}0.363 \\
(0.003)\end{array}$ & 0.373 & $\begin{array}{l}0.264 \\
(0.000)\end{array}$ & 0.11 & $\begin{array}{c}-0.097 \\
(0.000)\end{array}$ & 0.06 & $\begin{array}{l}0.076 \\
(0.000)\end{array}$ & 0.04 \\
\hline
\end{tabular}




\subsection{Additional robustness analyses: reference point specification}

As previously underscored, given that the literature is still largely silent on the way a stock option holder would set and adapt his reference point, the specification of the latter is the main aspect that may affect the robustness of the empirical results. To this regard, I performed a robustness analysis based on alternative specifications of the reference point. The common assumption underlying these alternative specifications states that the employee relies on the BS value of the option to set the reference point. Actually, the intuition behind this assumption is supported by mainstream practices in terms of stock option-based compensation. Most of stock options designers use the BS model in order to estimate their values as constituents of the employees total compensation packages. These values are usually announced to the employee at the inception of the plans. Moreover, the BS model is recommended in the FASB and the IASC guidelines for determining the stock options fair value that needs to be disclosed in the financial statements. These statements are provided to shareholders as well as to stakeholders including employees.

The first alternative specification (AS\#1) is the current BS value of the option, denoted by " $\pi($.$) ",$ based on the stock price corresponding to the employee own expectation regarding the annualized stock price return " $\rho$ " over the option lifetime. The only difference between this specification and the original one is that it uses the BS value of the option rather than its intrinsic value:

$$
\theta_{i}=\pi\left(S e^{(\rho-q) i \delta t}, K, \sigma, r, q, T-i \delta t\right)
$$

The second alternative (AS\#2) assumes that the reference point is set in a static way at a proportion " $\rho$ " of the BS value at the inception of the option:

$\theta_{i}=\rho \pi(S, K, \sigma, r, q, T)$

In the last alternative (AS\#3) the reference point is specified as a fraction " $\rho$ " of the current BS value of the option based on the spot price of the stock floored by its price at inception:

$$
\theta_{i, j}=\rho \pi\left[\left(S, S u^{i} d^{i-j}\right)^{+}, K, \sigma, r, q, T-i \delta t\right]
$$

The common point in all these alternative specifications is that the reference point becomes dependent on the volatility of the stock price. However, while the second alternative is a static specification of the reference point that conveys the fact that the starting point is usually privileged in a benchmark role (Spranca et al., 1991), the first and the last alternatives are dynamic. Specifically, the last alternative is a stochastic specification of the reference point. Consistent with Arkes et al. (2006) findings that people tend to adapt their reference points asymmetrically more completely over 
gains than over losses, this specification assumes that the reference point is adjusted to the spot price of the stock only if the latter is above its starting level at the option grant date.

Table-6: Base case calibration of the alternative specifications

This table presents the base calibration results of the CPT model alternative specifications regarding the reference point. The upper block includes the parameters estimates yielded by the calibration. The middle block comprises the calibrations errors " $\varepsilon$ " and the related $x 2$ significance test p-values, where the null hypothesis is "H0: $\varepsilon \neq 0$ ". The bottom block reports the model forecasts of the exercise variables implied by each calibration, including the expected cancellation rate and the conditional expectations of the stock price exercise ratios and the exercise timing, and the resulting value of the average stock option contract. A “*”, "*** or “***" indicates significance at the $10 \%, 5 \%$ or $1 \%$ level, respectively.

\begin{tabular}{|c|c|c|c|c|}
\hline Calibration outputs & $\begin{array}{c}\text { Original } \\
\text { specification }\end{array}$ & AS \#1 & AS\#2 & AS \#3 \\
\hline$\hat{p}_{e}$ & 0.04 & 0.04 & 0.04 & 0.04 \\
\hline$\hat{\rho}$ & $22 \%$ & $21 \%$ & $34 \%$ & $18 \%$ \\
\hline$\hat{y}$ & 0.23 & 0.23 & 0.24 & 0.23 \\
\hline$\hat{a}$ & 0.69 & 0.65 & 0.71 & 0.60 \\
\hline$\hat{\lambda}$ & 2.25 & 2.25 & 2.25 & 2.25 \\
\hline$\hat{\alpha}$ & 0.88 & 0.88 & 0.88 & 0.88 \\
\hline Calibration error: $\varepsilon(a, \rho, q, y)$ & $0.0012 * * *$ & $0.0012 * * *$ & $0.0011 * * *$ & $0.0011^{* * *}$ \\
\hline${ }^{2} \times$ test $(p$-value $)$ & 0.001 & 0.001 & 0.001 & 0.001 \\
\hline$\hat{S_{\tau}}$ & 2.46 & 2.46 & 2.45 & 2.46 \\
\hline$\hat{\tau}$ & 6.46 & 6.37 & 7.43 & 4.61 \\
\hline$\hat{\eta}$ & $5.47 \%$ & $5.46 \%$ & $5.49 \%$ & $5.48 \%$ \\
\hline Option fair value & 0.390 & 0.389 & 0.389 & 0.389 \\
\hline
\end{tabular}

I calibrated all the model alternative specifications using the base case approach. The calibration results are reported in table- 6 . The calibration error statistics indicate that all of the calibrations are significant at the $1 \%$ level. In the case of AS\#2, the reference point parameter estimate " $\hat{\rho}=34 \%$ " signals that, assuming the employees in the sample would set their reference point accordingly, they will refer to a fraction of the BS value rather than to the full value. The same conclusion could be drawn from the parameter estimate yielded by the calibration of AS\#3. In the case of AS\#1, the reference point parameter estimate supports that the employee would set his reference point at a BS value based on a stock price level resulting in an average return of $21 \%$ per annum since the option inception. This estimate is close to that obtained in the original specification. The difference could be interpreted as a downside adjustment due to the time value component embedded in the BS value.

In order to compare the alternative specifications in terms of the predictive performance, I performed the same in-sample comparative analysis. Broadly, the results show that the specification originally used in the model do as well as AS\#1 but outperforms the other alternatives in terms of the size of the average forecast errors. Specifically, AS\#1 yields mean forecast errors that are nearly equivalent to those of the original specification, given that the difference is not statistically significant. Its regression $\mathrm{R}^{2}$ is slightly lower than that of the original specification. By contrast, the stochastic specification of the reference point (A\#3) turns out to have the highest mean forecast errors, but improves in turn the linear adjustment of the empirical stock price exercise ratio. 
Table-7: Comparing the performance of the reference point specifications

This table reports the results of the in-sample comparison of the CPT model reference point specifications. Mean variable of interest in this analysis is the exercise stock price ratio. The forecasting performance of each specification is assessed based on the Mean Squared Percentage Error (MSPE), the Mean Absolute Percentage Error (MAPE) and the outputs of the OLS regression of the variables observed values over the model predictions. The meaningfulness of the differences between the average forecast errors of the original specification and those from the alternative specifications is formally tested using the impaired unilateral Student's t-test.

\begin{tabular}{|l|c|c|c|c|}
\hline \multirow{2}{*}{ Models comparisons } & Forecast Errors Statistics & \multicolumn{2}{c|}{ OLS analysis } \\
\cline { 2 - 5 } & MSPE & MAPE & $\beta$ & $R^{2}$ \\
\hline Panel-1: Original specification & 1.065 & 0.589 & 0.381 & 0.15 \\
Panel-2: AS \#1 & & & $(0.000)$ & 0.13 \\
t-test against the original specification & 1.069 & 0.593 & 0.343 & \multirow{2}{*}{0.19} \\
Panel-3: AS \#2 & $(0.384)$ & $(0.262)$ & $(0.000)$ & \multirow{2}{*}{0.21} \\
t-test against the original specification & 1.919 & 0.677 & 0.508 & \\
Panel-5: AS \#3 & $(0.000)$ & $(0.000)$ & $(0.000)$ & 0.486 \\
t-test against the original specification & 1.924 & 0.677 & $(0.000)$ & \\
\hline
\end{tabular}

In summary, this analysis confirms the robustness of the empirical results in this paper with respect to the reference point specification. The conclusions drawn from this robustness analysis are also consistent with Hodge et al. (2010) findings that employees usually use heuristics to attach values to their stock options, like determining the intrinsic value from their expectations about the future stock price.

\section{Implications for fair value assessment}

The international accounting standards (IFRS 2) and the US GAAP (ASC Topic 718) require the recognition of the stock option grants costs in the financial statements at their fair values. According to the standards guidelines, the fair value of the contract has to be determined at the grant date of the option. In the special case of the cash settled contracts, suck like the Stock Appreciation Rights (SAR), the fair value has to be reassessed at each reporting date. These standards also recommend the implementation of the widely used and commonly accepted valuation approaches. Specifically, the ASC Topic 718 (ex SFAS 123R ${ }^{12}$ ) states that a lattice model and a closed-form model are valuation techniques meeting its criteria for estimating fair values of employee stock options, specifically mentioning the binomial model and the adjusted BS formula as examples of each, respectively. Although the statement does not specify a preference for a particular valuation technique, in practice ${ }^{13}$ most of the firms use tweaked binomial models as well as the BS model adjusted to the expected lifetime of the options. Unfortunately, these approaches disregards employee risk preferences patterns and, therefore, still do not accurately handle actual exercise behavior.

\footnotetext{
${ }^{12}$ SFAS $123 R$ paragraph A13.

${ }^{13}$ DUFF \& PHELPS (2009) IFRS 2 implementation survey shows for instance that almost 85\% of the FTSE 100 companies use the BS model and binomial approaches to value complex equity based compensation schemes including stock options.
} 
In order to compare the option faire values ${ }^{14}$ under each of the three competing models, I assessed the fair values of the 542 stock option contracts in the sample at their respective grant dates. For that, I used the base case calibrations. In addition, for the purpose of comparison with some methods recommended by the accounting standards and largely used by practitioners, I computed option fair values using two benchmark models. The first one is the adjusted BS formula (ABS). This is an extension of the BS model that uses as input the expected lifetime of the option instead of its contractual expiration date. The second benchmark is the Hull and White (2004) model (HW). This model assumes that a vested option is exercised whenever the underlying stock price hits a given hurdle (also called a suboptimal factor) from below. It also allows for the possibility of exit events, pre vesting and post vesting, due to exogenous factors causing forfeiture or early exercise of the option. The suboptimal factor in the HW model is set equal to the average exercise stock price ratio in the sample (i.e. 2.46). The exit rates, pre and post vesting, are set equal to the average cancellation rate (i.e. 6.30\%). The ABS value is based on the average lifetime of the options (i.e. 4.30). In complement to this, I transposed the analysis to the out-of-sample setting using the calibration based on the average data from the middle quintile (Q3). This analysis involves 503 plans instead.

Table- 8 reports the spreads (as $\%$ of the strike prices) between the fair value estimates from the aforementioned models. As we can see from the base case calibration figures in panel-1, the EA model yields significantly lower values compared to the two other models (an average of almost $-6.5 \%$, hence an accounting cost impact of $-\$ 5.2 \mathrm{M}$ over all the plans). The fair value estimates from the CPT model and those yielded by the EU model are also different at the $1 \%$ significance level. The estimates from the EU model are on average 1\% lower than CPT model yielded values (hence an impact of $\$ 1 \mathrm{M})$. On the other hand, the values from these two models are significantly higher than the values computed based on the benchmark approaches. Specifically, if we consider that the CPT model is the most accurate model in the sense that it better predicts the stock price exercise ratios, we would admit that the benchmark models underestimate the values of the stock options by $4 \%$ to $13 \%$ on average, which implies an accounting cost lag ranging from $\$ 4 \mathrm{M}$ to $\$ 11 \mathrm{M}$ for the whole sample. Further, the out-of-sample analysis (see panel-2) leads also to the conclusion that the benchmarks-yielded fair value estimates are lower than those from the CPT model at the $1 \%$ significance level. However, the value spreads tighten, specifically with respect to the HW against which the accounting impact reduces substantially to $-\$ 660 \mathrm{~K}$. Furthermore, the CPT model still yield higher values than those from the EA model, while the average value spread against the EU model turns positive at the $1 \%$ significance level, which implies a small accounting gap of $\$ 67 \mathrm{~K}$. This means that the related result

\footnotetext{
${ }^{14}$ Note that while the approach used here does not strictly follow the accounting standards guidelines in terms of the measurement of the fair value of the option, instead of the total cost of the grant, it provides however the cost per granted option. Actually, IFRS 2 makes a distinction between market based performance features and nonmarket features. Market based performance features should be included in the grant-date fair value measurement. However, the fair value of the equity instruments should not be reduced to take into consideration non-market factors or other vesting features. By contrast, fair values from our three competing models integrate cancellations due to the non-market factors.
} 
obtained earlier from the in-sample analysis is not robust. Arguably one would expect both models to lead to comparable stock option fair value cost assessment.

\section{Table-8: Comparing option fair value estimates}

This table provides a comparative analysis of the values of the stock option contracts from each model. The analysis involves the 542 plans in the sample. The market parameters specific to each company were estimated at the grant dates as described in §4.1.2. Panel-1 reports the average spreads between the in-sample value estimates as a \% of the strike price (row model values minus column model values) based on the base case calibration of the models. Panel-2 exhibits the same statistics out-of-sample based on the Q3 calibration of the models. The values are also compared to those from the Hull and White (2004) model (HW) and the adjusted BS approach (ABS). The suboptimal factor in the HW model is set equal to the average stock price exercise ratio in the sample (i.e. 2.46). The values of the exit rates pre and post vesting are set to the average cancellation rate in panel-1 (i.e. 6.30\%). The ABS value is based on the average lifetime of the options (i.e. 4.30). Asymptotic t-statistics are in parentheses. A “*”, “**” and “***” indicate significance at the $10 \%, 5 \%$ and $1 \%$ levels respectively.

\begin{tabular}{|c|c|c|c|c|c|}
\hline & CPT & EU & EA & HW & ABS \\
\hline \multicolumn{6}{|l|}{ Panel-1: In-sample } \\
\hline \multirow{2}{*}{ CPT } & 0.000 & & & & \\
\hline & $n / a$ & & & & \\
\hline \multirow{2}{*}{$\mathbf{E U}$} & $-0.013 * * *$ & 0.000 & & & \\
\hline & $(-121.94)$ & $n / a$ & & & \\
\hline \multirow{2}{*}{ EA } & $-0.070 * * *$ & $-0.057 * * *$ & 0.000 & & \\
\hline & $(-167.43)$ & $(-170.46)$ & $n / a$ & & \\
\hline \multirow{2}{*}{ HW } & $-0.044 * * *$ & $-0.031 * * *$ & $0.026 * * *$ & 0.000 & \\
\hline & $(-132.49)$ & $(131.71)$ & $(124.94)$ & $n / a$ & \\
\hline \multirow{2}{*}{ ABS } & $-0.125 * * *$ & $-0.113 * * *$ & $-0.055 * * *$ & $-0.081 * * *$ & 0.000 \\
\hline & $(-169.56)$ & $(-171.60)$ & $(-158.21)$ & $(-174.51)$ & $n / a$ \\
\hline \multicolumn{6}{|l|}{ Panel-2: Out-of-sample } \\
\hline \multirow{2}{*}{ CPT } & 0.000 & & & & \\
\hline & $n / a$ & & & & \\
\hline \multirow{2}{*}{$\mathbf{E U}$} & $0.001 * * *$ & 0.000 & & & \\
\hline & $(12.53)$ & $n / a$ & & & \\
\hline \multirow{2}{*}{ EA } & $-0.042 * * *$ & $-0.043 * * *$ & 0.000 & & \\
\hline & $(-160.57)$ & $(-162.26)$ & $n / a$ & & \\
\hline \multirow{2}{*}{ HW } & $-0.008 * * *$ & $-0.009 * * *$ & $0.034 * * *$ & 0.000 & \\
\hline & $(-37.33)$ & $(-46.21)$ & $(124.30)$ & $n / a$ & \\
\hline \multirow{2}{*}{ ABS } & $-0.097 * * *$ & $-0.098 * * *$ & $-0.055 * * *$ & $-0.089 * * *$ & 0.000 \\
\hline & $(-168.35)$ & $(-169.19)$ & $(-157.60)$ & $(-175.10)$ & $n / a$ \\
\hline
\end{tabular}

\section{Conclusion}

This research draws on the CPT framework to develop an alternative theoretical model for the exercise and the valuation of employee stock options. The central question examined in the paper is the following: are employees exercise decisions better explained through the CPT compared to the EUT and the standard American options theory? The related subsidiary question is how this new representation of the exercise behavior would affect the stock options cost to shareholders?

The central result of this paper is that the model predictions ascertain the ability of the CPT to better explain the exercise decisions than the aforementioned theories. This finding conveys the main contribution of the paper which is the strong ability of the CPT framework to explain some prominent patterns in the employee exercise behavior. It therefore provides rationale for using the CPT framework in order to get more accurate fair value estimates of employee stock options contracts. By 
admitting this, I proved that the methods recommended by the accounting standards and largely adopted by practitioners would potentially lead to an underestimate of the stock options cost to shareholders.

The major implication of these results lies within the area of fair value measurement issues. It outlines the relevance of behavioral valuation models for achieving meaningful fair value estimates. More broadly, the results in this work underscore the importance of gaining a thorough understanding of the behavioral factors underlying employees exercise decisions in order to get comprehensive, and more apparent, perspectives on their economic consequences. These include for instance the cash impacts (resp. dilution impacts) due to the early exercise of cash settled (resp. equity settled) stock options.

Another interesting result in this work is given by the probability weighting coefficients yielded by the model calibrations. These estimates turn out to be consistent with those from the experimental literature. This suggests that the exercise behavior is likely to conceal an optimism or a pessimism bias. This finding has a far reaching implication for employee sentiments representation. While some recent papers used stock options exercise timing as a proxy to behavioral biases, such as overconfidence (Malmendier and Tate, 2005, 2008), I believe that the information in the probability weighting parameters estimates from stock options exercise time series could be used to build more relevant measures of employee sentiments towards very positive (resp. very negative) events. I leave this investigation to future work.

Due to the model specification, this research has some natural limitations that have to be outlined. The first one relates to the specification of the reference point. Actually, the literature is still silent on how people set reference points when assessing complex gambles like stock option payoffs, which stands for a handicap in applying the CPT. In the absence of such guidance I tested specifications consistent with both empirical evidence on people setting reference points in a dynamic fashion and firms' widespread use of the BS value in financial and employees compensation disclosers. Moreover, the model does not handle the resetting and the reloading provisions that are used in some stock options contracts. The model could however be enhanced in order to parsimoniously integrate factors representing these provisions as suggested in a recent literature (Brenner et al., 2000; Sircar and Xiong, 2006). The last limitation is due to the representative employee setting that ignores the heterogeneity of beliefs. However, this issue needs to be put into perspective along with the finding in Jouini and Napp (2012) showing that an agent with an inverse-S shaped probability weighting function (as in the CPT) may be represented as a collection of agents with noisy beliefs. 


\section{Appendices}

\section{Appendix A1: Construction of the decision weights tree}

In this appendix we address the problem of the construction of a decision weights tree using the CPT probability weighting function. Let " $p_{i, j}$ " be the upward transition decision weight at node $(i, j)$, " $\bar{p}_{i, j}$ " is the corresponding downward transition decision weight and " $\lambda_{i, j}$ " is the weighted probability to reach the node. The latter is computed either from compounding transition decision weights related to the previous adjacent nodes or from weighting the binomial probability of reaching the node as described in (3) and (4). The transition decision weights are retrieved over the entire tree starting from level 0 towards level $N-1$ based on the following algorithm:

- For $i=0$ :

$\lambda_{0,0}=1$

$\omega_{1,0}=\psi_{a}(1-p)$

$p_{0,0}=1-\frac{\omega_{1,0}}{\lambda_{0,0}}$

$\bar{p}_{0,0}=1-p_{0,0}$

- For $i>0$ :

- For $0<j<i$ :

$\lambda_{i, j}=p_{i-1, j-1} \lambda_{i-1, j-1}+\bar{p}_{i-1, j} \lambda_{i-1, j}$

$\omega_{i+1, j}=\psi_{a}\left(\sum_{k=0}^{j}\left(\begin{array}{l}i+1 \\ k\end{array}\right) p^{k}(1-p)^{i+1-k}\right)-\psi_{a}\left(\sum_{k=0}^{j-1}\left(\begin{array}{l}i+1 \\ k\end{array}\right) p^{k}(1-p)^{i+1-k}\right)$

$p_{i, j}=1-\frac{\omega_{i+1, j}-p_{i, j-1} \lambda_{i, j-1}}{\lambda_{i, j}}$

$\bar{p}_{i, j}=1-p_{i, j}$

- For $j=0$ :

$\lambda_{i, 0}=\bar{p}_{i-1,0} \lambda_{i-1,0}$

$\omega_{i+1,0}=\psi_{a}\left((1-p)^{i+1}\right)$

$p_{i, 0}=1-\frac{\omega_{i+1,0}}{\lambda_{i, 0}}$

$\bar{p}_{i, 0}=1-p_{i, 0}$ 


$$
\begin{gathered}
- \text { For } j=i: \\
\lambda_{i, i}=p_{i-1, i-1} \lambda_{i-1, i-1} \\
\omega_{i+1, i+1}=1-\psi_{a}\left(1-p^{i+1}\right) \\
p_{i, i}=\frac{\omega_{i+1, i+1}}{\lambda_{i, i}} \\
\bar{p}_{i, i}=\frac{\omega_{i+1, i}-p_{i, i-1} \lambda_{i, i-1}}{\lambda_{i, i}}
\end{gathered}
$$

\section{Appendix A2: CPT model algorithm}

This appendix exhibits the algorithm of the CPT model. Let us use the following notations:

- $h_{i, j}$ : Intrinsic value of the option at note $(i, j)$.

- $p_{i, j}$ : Upward transition decision weight at node $(i, j)$ determined following the methodology in Appendix A1.

- $\bar{p}_{i, j}$ : Downward transition decision weight at node $(i, j)$ determined following the methodology in Appendix A1.

- $p^{*}$ : Risk neutral transition probability at node $(i, j)$.

- $C e_{i, j}$ : Subjective value of the option at node $(i, j)$ determined based on the certainty equivalence principle.

- $C_{i, j}$ : Risk-neutral value of the option at node $(i, j)$.

- $V_{i, j}^{0}$ : Continuing state exercise decision outcome at node $(i, j)$.

- $V_{i, j}^{1}$ : Exit state exercise decision outcome at node $(i, j)$.

- $p_{e}$ : Exit probability.

- $\theta_{i}$ : Reference point at the $i^{\text {th }}$ level.

In addition, let the decision function “ $E_{i, j}^{m \in\{0,1\} "}$ represent the exercise policy of the employee at both the continuing state $(m=0)$ and the exit state $(m=1):{ }^{“} E_{i, j}^{m \in\{0,1\}}=1$ " if the employee exercises the option and " $E_{i, j}^{m \in\{0,1\}}=0$ " otherwise. The exercise policy yielded by the CPT model implies the riskneutral value of the option " $C_{i, j}$ ". It is defined recursively following the algorithm below: 
- For $t_{i} \geq t_{v}$ :

$$
\begin{aligned}
& E_{i, j}^{0}=1 \mathrm{I}_{\left\{h_{i, j}>c c_{i, j}\right\}} \\
& E_{i, j}^{1}=1 \mathrm{I}_{\left\{\left(h_{i, j}+y\right)>C c_{i, j}\right\}} \\
& V_{i, j}^{0}=C_{i, j}\left(1-E_{i, j}^{0}\right)+h_{i, j} E_{i, j}^{0} \\
& V_{i, j}^{1}=C_{i, j}\left(1-E_{i, j}^{1}\right)+h_{i, j} E_{i, j}^{1} \\
& -\quad F o r t_{i}<t_{v}: \\
& E_{i, j}^{0}=0 \\
& E_{i, j}^{1}=1 \mathrm{I}_{\left\{y>C c_{i, j}\right\}} \\
& V_{i, j}^{0}=C_{i, j} \\
& V_{i, j}^{1}=C_{i, j}\left(1-E_{i, j}^{1}\right)
\end{aligned}
$$

Where:

$t_{i}=i \delta t$

$\theta_{i}=\left(S e^{(\rho-q) i \delta t}-K\right)^{+}$

$h_{i, j}=\left(S u^{i} d^{i-j}-K\right)^{+}$

$C_{i, j}=\left[\left(1-p_{e}\right)\left(p^{*} V_{i+1, j+1}^{0}+\left(1-p^{*}\right) V_{i+1, j}^{0}\right)+p_{e}\left(p^{*} V_{i+1, j+1}^{1}+\left(1-p^{*}\right) V_{i+1, j}^{1}\right)\right] e^{-r \delta t}$

$C e_{i, j}=v_{\theta_{i}}^{-1}\left[\left(1-p_{e}\right)\left(p_{i, j} v_{\theta_{i+1}}\left(V_{i+1, j+1}^{0}\right)+\bar{p}_{i, j} v_{\theta_{i+1}}\left(V_{i+1, j}^{0}\right)\right)+p_{e}\left(p_{i, j} v_{\theta_{i+1}}\left(V_{i+1, j+1}^{1}\right)+\bar{p}_{i, j} v_{\theta_{i+1}}\left(V_{i+1, j}^{1}\right)\right)\right] e^{-r \delta t}$

$v_{\theta}^{-1}(x)=\left\{\begin{array}{l}\theta+x^{\frac{1}{\alpha}} ; \quad x \geq 0 \\ \theta-\left(-\frac{x}{\lambda}\right)^{\frac{1}{\alpha}} ; x<0\end{array}\right.$, with $0<\alpha \leq 1$ and $\lambda \geq 1$

\section{References}

[1] Arkes H. R. and Blumer C. (1985), The psychology of sunk cost, Organizational Behavior and Human Decision Processes, Vol. 35, No. 1, pp.124-140.

[2] Armstrong C., Jagolinze A. and Larcker D. (2006), Timing of employee stock option exercises and the valuation of stock option expense, Working Paper, Stanford University.

[3] Bahaji H. (2011), Incentives from stock option grants: a behavioral approach, Review of Accounting and Finance, Vol. 10, No. 3, pp.200-227.

[4] Bettis J., Bizjak J. and Lemmon M. (2005), Exercise behavior, valuation and the incentive effects of employee stock options, Journal of Financial Economics, Vol. 76, No. 2, pp.445470. 
[5] Brenner M., Sundaram R. and Yermack D. (2000), Altering the terms of executive stock options, Journal of Financial Economics, Vol. 57, No. 1, pp.103-128.

[6] Carpenter J. (1998), The exercise and valuation of Executive stock options, Journal of Financial Economics, vol. 48, No. 2, pp.127-158.

[7] Carpenter J., Stanton R. and Wallace N. (2006), Estimation of Employee Stock Option Exercise Rates and Firm Cost: Methodology, Working Paper, New York University.

[8] Carpenter J., Stanton R. and Wallace N. (2010) Optimal Exercise of Executive Stock options and Implications for Firm Cost, Journal of Financial Economics, Vol. 98, No. 1, pp. 315-337

[9] Carr P. and Linetsky V. (2000), The valuation of executive stock options in an intensity based framework, European Financial Review, Vol. 4, No. 3, pp. 211-230.

[10] Chen H. and Rao A. (2002), Close encounters of two kinds: False alarms and dashed hopes, Marketing Science, Vol. 21, No. 2, pp.178-196.

[11] Core J.E. and Guay W. (2001), Stock option plans for non-executive employees, Journal of Financial Economics, Vol. 61, No. 2, pp.253-287.

[12] Cuny C. and Jorion P. (1995), Valuing executive stock options with an endogenous departure decision, Journal of Accounting and Economics, Vol. 20, No. 2, pp. 193-205.

[13] Cvitanic J., Wiener Z. and Zapatero F. (2004), Analytic pricing of employee stock options, Working paper, University of Southern California.

[14] Derman E. and Kani I. (1994), Riding on a smile, Risk, Vol. 7, No. 2, pp.32-39.

[15] Derman E., Kani I. and Chriss N. (1996), Implied Trinomial Trees of the volatility smile, Goldman Sachs Quantitative Strategies Research Notes, Goldman Sachs.

[16] Detemple J. and Sundaresan S. (1999), Nontraded asset valuation with portfolio constraints: A binomial approach, Review of Economic Studies, Vol. 12, No. 4, pp.835-872.

[17] Devers C., Wiseman R. and Holmes M. (2007), The effects of endowment and loss aversion in managerial stock option valuation, Academy of Management Journal, Vol. 50 No. 1, pp. 191208.

[18] Dittmann I. and Maug E. (2007), Lower salaries and no options? On the optimal structure of Executive pay, The Journal of Finance, Vol. 62, No. 1, pp.303-343.

[19] Dittmann I., Maug E. and Spalt O.G. (2010), Sticks or Carrots? Optimal CEO Compensation when Managers are Loss Averse, Journal of Finance, Vol. 65, No. 6, pp.2015-2050.

[20] DUFF \& PHELPS (2009), A study of the implementation of IFRS 2 by FTSE 100 companies in 2006 and 2007, White paper, London.

[21] Dybvig P. and Loewenstein M. (2003), Employee reload options: pricing, hedging, and optimal exercise, Review of Financial Studies, Vol. 16, No. 1, pp. 145-171.

[22] Gneezy U. (1998), Updating the Reference Level: Experimental Evidence, Working paper, University of Haifa.

[23] Grasselli M. and Henderson V. (2009), Risk Aversion and Block Exercise of Executive Stock Options. Journal of Economic Dynamics and Control, Vol. 33, No. 1, pp.109-127.

[24] Hall B. and Murphy K. (2000), Optimal Exercise prices for executive stock options, American Economic Review, Vol. 90, No. 2, pp. 209-214. 
[25] Hall B. and Murphy K. (2002), Stock options for undiversified executives, Journal of Accounting and Economics Vol. 33, No. 2, pp. 3-42.

[26] Hallock K. and Olson G. (2006), The value of stock options to non-executive employees, Working Paper, No. 11950, National Bureau of Economic Research, Cambridge.

[27] Heath C., Huddart S. and Lang M. (1999), Psychological factors and stock option exercise, Quarterly Journal of Economics, Vol. 114, No. 2, pp. 601-628.

[28] Heisler J. (1994), Loss aversion in a futures market: an empirical test, Review of Futures Markets, Vol. 13 No. 3, pp. 793-822.

[29] Henderson V. (2005), The impact of the market portfolio on the valuation, incentives and optimality of executive stock options, Quantitative Finance, Vol. 5, No. 1, pp. 35-47.

[30] Henderson V. (2006), Executive exercise explained: Patterns for stock options, Working paper, Princeton University.

[31] Hemmer S., Matsunaga S. and Shevlin T. (1996), The influence of risk diversification on the early exercise of employee stock options by executive officers, Journal of Accounting and Economics, Vol. 21, No. 1, pp.45-68.

[32] Hemmer T., Matsunaga S. and Shevlin T. (1998), Optimal exercise and the cost of granting employee stock options with a reload provision, Journal of Accounting Research, Vol. 36, No. 2, pp. 231-255.

[33] Hodge F. Rajgopal S. and Shevlin T. (2010), Do managers value stock options and restricted stock consistent with Economic theory? Contemporary Accounting Research, Vol.26, N³, pp. 899-932.

[34] Huddart S. (1994), Employee stock options, Journal of Accounting and Economics, Vol. 18, No. 2, pp.207-231.

[35] Huddart S. and Lang M. (1996), Employee stock option exercises: an empirical analysis, Journal of Accounting and Economics, Vol. 21 No. 1, pp. 5-43.

[36] Hull J. and White A. (2004), How to value employee stock options, Financial Analysts Journal, Vol. 60, No. 1, pp.114-119.

[37] Ibbotson Associates (2006), Stocks, Bonds, Bills, and Inflation, Valuation Edition, 2006 Yearbook.

[38] Ingersoll J. (2008), Non-Monotonicity of the Tversky-Kahneman Probability-Weighting Function: A Cautionary note, European Financial Management, Vol. 14, No. 3, pp.385-390.

[39] Jennergren L. and Naslund B. (1993), A comment on "Valuation of executive stock options and the FASB proposal", The Accounting Review, Vol. 68, No. 1, pp.179-183.

[40] Jenter D. (2001), Understanding high-powered incentives, Working Paper, Harvard Business School and Economics Department.

[41] Jouini E. and Napp C. (2012), Behavioral biases and the representative agent, Theory and Decision, Vol. 73, N¹, pp 97-123.

[42] Kahneman D. and Tversky A. (1979), Prospect Theory: An analysis of decision under risk, Econometrica, Vol. 47 No. 2, pp. 263-292.

[43] Koszegi B. and Rabin M. (2006), A model of reference-dependent preferences, The Quarterly Journal of Economics, Vol. 121, No. 4, pp.1133-1166. 
[44] Kulatilaka N. and Marcus A. (1994), Valuing Employee Stock Options, Financial Analysts Journal, vol. 50, No. 5, pp.46-56.

[45] Lambert R., Larcker D. and Verrecchia R. (1991), Portfolio considerations in valuing Executive Compensation, Journal of Accounting Research, Vol. 29, No. 1, pp. 129-149.

[46] Lambert R. and Larcker D. (2001), How do employees value (often incorrectly) their stock options? available at: knowledge@wharton.

[47] Malmendier U. and Tate G. (2005), CEO Overconfidence and Corporate Investment, Journal of Finance, Vol. 60, $\mathrm{N}^{\circ}$ 6, pp. 2661-2700.

[48] Malmendier U. and Tate G. (2008), Who Makes Acquisitions? CEO Overconfidence and the Market's Reaction, Journal of Financial Economics, Vol. 89, N 1 , pp. 20-43.

[49] Misra L. and Shi Y. (2005), Option exercise by CEOs: overconfidence VS market timing, Working Paper, Texas University.

[50] Odean T. (1998), Are Investors Reluctant to Realize their Losses? Journal of Finance, Vol. 53 No. 5, pp. 1775-1798.

[51] Polkovnichenko V. and Zhao F. (2013), Probability weighting functions implied in options prices, Journal of Financial Economics, Vol.107, N3, pp.580-609.

[52] Quiggin J. (1982), A theory of anticipated utility, Journal of Economic Behavior and Organization, Vol. 3, №4, pp 323-343.

[53] Rubinstein M. (1994), Implied Binomial Trees, Journal of Finance, Vol. 69, No. 3, pp.771818.

[54] Rubinstein M. (1995), On the accounting valuation of employee stock options, The Journal of Derivatives, Vol. 3, No. 1, pp.8-24.

[55] Saly P.J., Jagannathan R. and Huddart S. (1999), Valuing the reload features of executive stock options, Accounting Horizons, Vol. 13, No. 3, pp.219-240.

[56] Shefrin H. and Statman M. (1985), The disposition to sell winners too early and ride losers too long: theory and evidence, Journal of Finance, Vol. 40 No. 3, pp. 777-790.

[57] Sircar R. and Xiong W.(2006), A General Framework for Evaluating Executive Stock Options, Working paper, Princeton University.

[58] Spalt O. (2013), Probability Weighting and Employee Stock Options, Journal of Financial and Quantitative analysis, Forthcoming.

[59] Spranca M., Minsk E. and Baron J. (1991). Omission and commission in judgment and choice. Journal of Experimental Social Psychology, Vol. 27, No. 1, pp.76-105.

[60] Yogo M. (2008), Asset prices under rising aspirations and reference-dependent preferences, Journal of Business and Economic Statistics, Vol. 26, pp.131-143. 